\title{
Cellulose aerogel composites as oil sorbents and their regeneration
}

\author{
Tatjana Paulauskiene ${ }^{\text {Corresp., } 1}$, Jochen Uebe ${ }^{1}$, Mindaugas Ziogas ${ }^{1}$ \\ ${ }^{1}$ Department of Engineering/Faculty of Marine Technology and Natural Science, Klaipeda University, Klaipeda, Lithuania \\ Corresponding Author: Tatjana Paulauskiene \\ Email address: tatjana.paulauskiene@ku.It
}

Background. With every oil tanker comes the risk of an accident and oil spill. Sorbents are the most suitable means to remove oil spills. Aerogels as sorbents have high porosity and can be made from cellulose from paper waste. The literature does not distinguish between paper and cardboard as sources of cellulose aerogels and little is known about composites of cellulose aerogels consisting of cellulose fibres and chemically untreated, unprocessed fibres or particles of straw, wool, macroalgae or cellulose acetate from cigarette butts. In this study, the sorption properties for marine diesel oil and biodiesel of such aerogels and their regenerative capacity with bioethanol were investigated.

Methods. Cellulose aerogels were prepared from office paper and cardboard waste without and with chemically untreated algae, straw, wool and cellulose acetate as a composite by freeze drying. All samples were hydrophobised with methylsilane. The density to calculate the porosity and the contact angle were determined. Then the sorption capacity was determined over 5 cycles of sorption of oil and regeneration with bioethanol.

Results. The average contact angle of all samples was $125^{\circ}$, indicating hydrophobicity. Paper-based aerogels were found to consistently have higher sorption capacities for biodiesel, marine diesel oil and bioethanol than cardboard-based aerogels. In particular, the wool/cellulose aerogel composite was found to have better sorption capacity for biodiesel, marine diesel oil and bioethanol than all other samples. The cellulose acetate/cellulose aerogel composite showed significantly higher sorption capacities than the paper and cardboard control samples (highest value is $32.25 \mathrm{~g} \mathrm{~g}^{-1}$ ) only when first used as a sorbent for biodiesel, but with a rapid decrease in the following cycles. 
1 Cellulose Aerogel Composites as Oil Sorbents and 2 their Regeneration

3

\section{Abstract} cycles oil clean-up

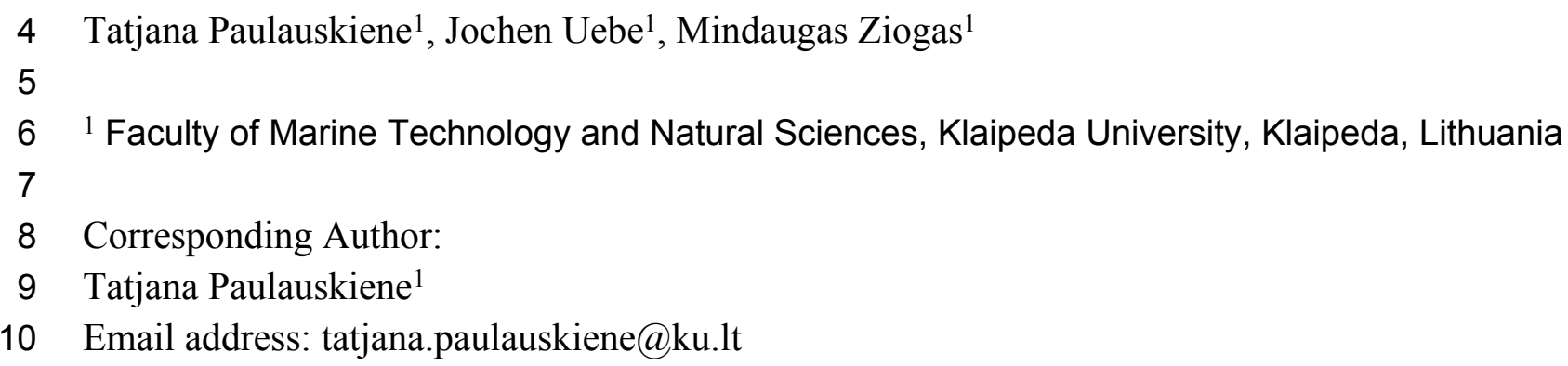

8 Corresponding Author:

9 Tatjana Paulauskiene ${ }^{1}$

Background. With every oil tanker, the risk of an accident and oil pollution increases. Sorbents are the most suitable means to remove oil spills. Aerogels as sorbents have high porosity and can be made from cellulose from paper waste. The literature does not distinguish between paper and cardboard as sources of cellulose aerogels and little is known about composites of cellulose aerogels consisting of cellulose fibres and chemically untreated, unprocessed fibres or particles of straw, wool, macroalgae or cellulose acetate from cigarette butts. In this study, the sorption properties for marine diesel oil and biodiesel of such aerogels and their regenerative capacity with ethanol were investigated.

Methods. Cellulose aerogels were prepared from office paper and cardboard waste without and with chemically untreated algae, straw, wool and cellulose acetate as a composite by freeze drying. All samples were hydrophobised with methylsilane. The density to calculate the porosity and the contact angle were determined. Then the sorption capacity was determined over 5 cycles of sorption of oil and regeneration with ethanol

Results. The average contact angle of all samples was $125^{\circ}$, indicating hydrophobicity. Paperbased aerogels were found to consistently have higher sorption capacities for biodiesel, marine diesel oil and ethanol than cardboard-based aerogels. In particular, the wool/cellulose aerogel composite was found to have better sorption capacity for biodiesel, marine diesel oil and ethanol than all other samples. The cellulose acetate/cellulose aerogel composite showed significantly higher sorption capacities than the paper and cardboard control samples (highest value is $32.25 \mathrm{~g}$ $\mathrm{g}^{-1}$ ) only when first used as a sorbent for biodiesel, but with a rapid decrease in the following

Keywords: cellulose aerogel composite; paper and cardboard waste; sorption capacity; oil spill; 
39

40

41

42

43

44

45

46

47

48

49

50

51

52

53

54

55

56

57

58

59

60

61

62

63

64

65

66

67

68

69

70

71

72

73

74

75

76

77

\section{Introduction}

As the countries around the Baltic Sea need large quantities of oil and other fuels, there are efforts to transport more cargo with larger ships (Gilek et al., 2016). This increases the risk of accidents and can lead to large amounts of spilled oil (Wang et al., 2014). When a spill occurs, it is important to clean it up as soon as possible to minimise the damage to nature. Oil spills spread under the influence of wind and water currents and undergo a series of chemical and physical changes that are influenced by a number of factors such as oil properties, weather conditions and geography (Saadoun, 2014).

One of the most sustainable methods of removing oil spills is the use of sorbents $(\mathrm{Li}, \mathrm{Liu} \&$ Yang, 2013). As sorbents have been used for many years, there are a number of requirements for their properties: they should be inexpensive, abundant, non-toxic, biodegradable and reusable. In addition, sorbents must have high specificity for the material to be absorbed, high sorption capacity and easy regeneration for reuse (Zamparas et al., 2020), (ITOPF).

Paulauskiene et al. (Paulauskiene et al., 2014) investigated natural sorbents such as straw, wool, moss, sawdust and peat for oil absorption. These materials achieved a sorption capacity of less than $10 \mathrm{~g} \mathrm{~g}^{-1}$ for diesel or crude oil. The disadvantage of natural sorbents is that they are dusty, difficult to use in windy conditions and have a low oil absorption capacity. In addition, some natural organic sorbents absorb not only oil but also water, causing the sorbents to sink ( $\mathrm{Li}$, Liu \& Yang, 2013).

Aerogels as sorbents have a much higher porosity and thus achieve a much higher sorption capacity (Hüsing \& Schubert, 1998). In addition, these materials can be subsequently modified by chemical vapour deposition (Chollon, Delettrez \& Langlais, 2014) so that, for example, their specificity for non-polar liquids is increased by hydrophobisation (Lin et al., 2015), (Li et al., 2014).

Cellulose is a renewable and biodegradable natural polymer most abundant in the world (Long, Weng \& Wang, 2018). The solvent of aerogels is replaced by air in the hydrogel, making cellulose-based aerogels environmentally friendly for humans and the environment (Zhang et al., 2015). As a cellulose source for aerogels, there are many possibilities such as plants and plant materials as well as their wastes (Long, Weng \& Wang, 2018). The use of paper waste (Nguyen et al., 2013), (Paulauskiene et al., 2020), the amounts of which are still increasing (Ferronato \& Torreta, 2019), (Meng-Chuen Chen et al., 2020), can be considered particularly sustainable, as the paper industry is one of the largest industries in the world (Demirel Bayik \& Altin, 2017). Interestingly, to the authors' knowledge, cardboard is mentioned as a source of cellulose aerogels in the known literature, but no one has actually explicitly and exclusively used cardboard upon closer inspection. (Long, Weng \& Wang, 2018) mention cardboard once in the introduction. Some primary industrial sources (Zhen et al., 2019), (Feng et al., 2015) are probably a mixture of paper and cardboard (Duong \& Nguyen, 2016). Paper and cardboard are made from the same raw material, but paper goes through a longer manufacturing process. The raw material for cardboard is less processed, which can also be seen in the coarser fibres when looking at it. 
78 (Ioelovich, 2014) has determined the differences between paper and cardboard in composition. 79 According to this, cardboard contains a significantly higher proportion of lignin of about $18 \%$ 80 and hemicellulose of $12 \%$, while office paper contains only about $1 \%$ lignin and $5 \%$

81 hemicellulose. The cellulose content is about the same, $61 \%$ for board and $62 \%$ for office

82 paper. Due to the manufacturing process, paper contains about $30 \%$ minerals in contrast to 83 cardboard with about $7 \%$.

84 Composites are prepared from at least two constituent materials. When aerogel composites are 85 reported, they are predominantly silica aerogel composites (Li et al., 2016), (Linhares, Pessoa de 86 Amorim \& Duraes, 2019) or so-called polymer aerogels, which are aerogel particles in a polymer 87 matrix (Xiao et al., 2020). This type includes cellulose composites, such as microalgae in a film 88 of cellulose (Yan et al., 2016), chemically treated straw in micropaper (Yousefi et al., 2011) or in 89 polymers (Wang, Qiao \& Sun, 2018), enzymatically treated wool in a cellulose acetate matrix 90 (Aluigi et al., 2008) or cellulose-coated wool fibres (Bridgeford \& Turbak, 1969), (Tran et al., 91 2016). Surprisingly, to the authors' knowledge, very little literature is known about composites of 92 particles of straw, wool, macroalgae or cellulose acetate from cigarette butts. To the authors' knowledge, only cellulose aerogel composites with graphene oxide have been reported (Zhang et al., 2012).

In this paper, the results of the investigation of aerogels from office paper and cardboard waste as composites with chemically untreated, virgin fibres or particles from straw, wool, algae and cellulose acetate (filter material of cigarettes) were analysed comparatively. Straw, wool, algae and cellulose acetate are easily accessible materials. The aim of their incorporation into cellulose aerogels is to modify the sorption capacities of cellulose aerogels, whereby these materials are incorporated into the cellulose fibres for the aerogels without prior treatment or dissolution. Straw, wool and the macroalga Cladophora were chosen because they are natural and cheap organic sorbents (but often disposed of as waste), biodegradable and their resources are renewable. Cellulose acetate is not natural and biodegrades slowly, but it is cheap. And it has already been produced as an aerogel and used as a sorbent for oil (Uebe, Paulauskiene \& Boikovych, 2021), (Ifelebuegu, 2018). The aerogel samples are hydrophobised with a silane reagent, creating a sorbent for oil. Density, porosity and hydrophobicity of the produced aerogels were determined. Furthermore, it was investigated whether an increase in the sorption properties of marine diesel and biodiesel can be measured by the additives. Finally, the regenerative capacity of the aerogels was characterised with ethanol, which is also environmentally friendly and sustainable. 


\section{Materials \& Methods}

\section{2.1 Materials used for the experiment}

116 For the production of the aerogels, office paper "Universal" with a grammage of $80 \mathrm{~g} \mathrm{~m}^{-2}$,

117 produced by The Navigator Company (Portugal), brownish 3-ply corrugated cardboard with a

118 grammage of $603 \mathrm{~g} \mathrm{~m}^{-2}$, purchased from UAB Dekpaka (Lietuva), and MoTip polyester resin

119 (MOTIP DUPLI Group, The Netherlands) were used as base materials. Trimethoxymethylsilane

120 (MTMS) with a purity of $98 \%$ (Sigma-Aldrich Chemie GmbH, U.S.) was used for

121 hydrophobisation and bioethanol with a purity of $99.5 \%$ (Merck KGaA, Germany) for

122 regeneration. The aerogel additives straw and sheep wool were sourced from a local farm near

123 Klaipeda (Lithuania). Cellulose acetate from cigarette filter production residues was provided by

124 UAB Philip Morris Lietuva. Cladophora macroalgae were collected from the northern beach of

125 Klaipeda (Lithuania) and subsequently air-dried.

126 For the determination of sorption capacities, marine diesel oil (MDO) with a density of $843 \mathrm{~kg}$

$127 \mathrm{~m}^{-3}$ and a dynamic viscosity of $0.0024 \mathrm{~Pa} \mathrm{~s}$ was provided by UAB "Gindana" (Lithuania) and

128 biodiesel with a density of $877 \mathrm{~kg} \mathrm{~m}^{-3}$ and a dynamic viscosity of $0.0038 \mathrm{~Pa}$ s was provided by

129 UAB "Mestilla" (Lithuania).

130

131

132

133

134

135

136

137

138

139

140

141

142

143

144

145

146

147

148

\subsection{Preparing the aerogel samples}

The scheme of aerogel production and examples of raw materials and additives used for aerogel production are shown in Figure 1.

Figure 1. Aerogels production scheme; examples of aerogels raw materials and additives: a) office paper; b) cardboard; c) wool; d) straw; e) algae; f) cellulose acetate

Office paper and cardboard were shredded to a size of $1 \mathrm{~cm}^{2}$, and the cellulose acetate cigarette filters, straw, seaweed and wool were shredded to about $0.5 \mathrm{~cm}$ in length. $200 \mathrm{ml}$ of a $1 \mathrm{wt} \%$ slurry of the shredded office paper or cardboard in distilled water was then prepared and homogenised for 20 minutes with a disperser (UltraTurrax T25 digital from IKA, stainless steel rotor/stator diameter of $18 \mathrm{~mm})$. After homogenisation, $1.2 \mathrm{ml}\left(1.1 \mathrm{wt} \%, \rho=1.145 \mathrm{~g} \mathrm{~cm}^{-3}\right)$ MoTip polyester resin and $0.2 \mathrm{~g}(0.33 \mathrm{wt} \%)$ additives such as wool, straw, algae or cellulose acetate were added to the mixture and homogenised for a further 5 minutes. The mixture was then poured into four $50 \mathrm{~mL}$ metal cup and cooled to minus $18^{\circ} \mathrm{C}$ for 4 hours. The frozen samples were then freeze-dried for 72 hours in vacuum at $0.015 \mathrm{hPa}$ and a condenser temperature of minus $105^{\circ} \mathrm{C}$ (ScanVac CoolSafe model pro, LaboGene). To hydrophobise the samples, MTMS ( $0.955 \mathrm{~g}$ per $1 \mathrm{~g}$ aerogel) was added to the bottom of a sufficiently large glass container in a small crystallising dish (Figure 2) and the samples were arranged vertically above it, 
149 separated with a plastic net. The glass container was covered on top with aluminium foil and 150 placed in the oven at $70^{\circ} \mathrm{C}$ for 12 hours.

151

152

153

154

156

157

158

159

160

161

162

163

164

165

166

167

168

169

170

171

172

173

174

Figure 2. Photograph of an aerogel modification: aerogel samples of office paper are white, aerogel samples of cardboard are brownish

\subsection{Measurements and calculations of aerogel properties}

Determination of the density and porosity. The densities $\rho_{l}$ of the samples were determined by weighing of a cuboid with known side lengths. Porosity of an aerogel was calculated as follows:

$$
\text { Porosity }=\left(1-\frac{\rho_{1}}{\rho_{2}}\right) \cdot 100, \%
$$

$\rho_{2}$ can be calculated according to the formula as also used by (Yan et al., 2016):

$$
\rho_{2}=\frac{1}{\frac{W_{\text {cellulose }}}{\rho_{\text {cellulose }}}+\frac{W_{\text {additive }}}{\rho_{\text {additive }}}}, \mathrm{g} \mathrm{cm}^{-3}
$$

$w_{\text {cellulose }}$ and $w_{\text {additive }}$ - parts of the cellulose and additive in the sample; $\rho_{\text {cellulose }}$ and $\rho_{\text {additive }}$ it is the densities of cellulose and additives. According to the literature, the density of cellulose is $1.50 \mathrm{~g} \mathrm{~cm}^{-3}$ (Pereira et al., 2020). The densities of the additives used in the production of the aerogel composites are $\left(\rho_{\text {additive }}\right)$ : algae $-1.02 \mathrm{~g} \mathrm{~cm}^{-3}$ (Zhu, Lu \& Dai, 2018), straw $-1.1 \mathrm{~g} \mathrm{~cm}^{-3}$ (Lam et al., 2007), wool - $1.3 \mathrm{~g} \mathrm{~cm}^{-3}$ (Kozyreff et al., 2003), and cellulose acetate $-1.3 \mathrm{~g} \mathrm{~cm}^{-3}$ (dos Santos et al., 2021).

Measurement of the water contact angle. The wettability of the aerogel surface was investigated by measuring the water contact angle $\theta$ using the sessile drop method. As described in (Paulauskiene et al., 2020), a high-resolution camera of a smartphone was used to take a closeup picture and the contact angle was calculated using the contact angle measurement software (protractor) based on the droplet shape image obtained.

Measurement of the maximum sorption capacity. The maximum sorption capacity of aerogels is a physical property of the aerogel to absorb maximum amount of liquid, in this case oils, into its pores at any given time. First aerogels samples were weighed $\left(m_{0}\right)$. Then aerogels samples were immersed in oil (biodiesel or marine diesel oil) for 5 minutes. The samples were then taken out from the oil, drained for 1 minute, and weighed again $\left(m_{1}\right)$. The maximum sorption capacity $(Q)$ of the oil was calculated as follows (Li et al., 2018a):

$$
Q=\frac{m_{1}-m_{0}}{m_{0}}, g g^{-1}
$$




\subsection{Ethanol regeneration study on aerogels}

176 Since the maximum sorption capacity for biodiesel and MDO is determined over several cycles,

177 the samples were regenerated with ethanol by the extraction method after each determination.

178 For the extraction, the samples were placed in a suitable plastic cup with a perforated bottom and

179 washed several times with ethanol. Subsequently, the samples were dried in a drying oven at

$18070^{\circ} \mathrm{C}$. The samples whose sorption capacity was determined by ethanol were dried in the drying

181 oven immediately after their determination.

182

183

184 Results

185

186

187

188

189

190

191

192

193

194

195

196

197

198

199

200

201

202

203

204

205

206

207

208

\section{Density and porosity calculations of the aerogel samples}

Although the same raw materials are used for cardboard and paper, the cellulose aerogels produced from them in this study differ in their properties. The aerogel samples made from office paper and from cardboard without any additives such as straw, wool, algae or cellulose acetate are referred to as control samples in the figures below. The densities of the control samples differ, which is reflected in a slightly different porosity, as shown in figures 3 and 4 . The densities and porosities of the composites, on the other hand, differ significantly from those of the control samples. They are on average consistently higher and correspondingly the porosities are on average consistently lower than those of the control samples.

Figure 3. Density of aerogels produced from office paper and cardboard with organic additives

Figure 4. Porosity of aerogels produced from office paper and cardboard with organic additives

\section{Hydrophobicity of aerogel samples}

It is known that paper and cardboard are hydrophilic. Infiltration with MTMS vapour makes the samples hydrophobic. MTMS can react with up to three hydroxy groups of the cellulose and thereby mask the formerly hydrophilic hydroxy groups with a hydrophobic methylsilane group.

Figure 5. Water droplet on a sample of aerogel: aerogel photo with water droplet on the top (a), close look to water droplet for contact angle with aerogel (b)

The contact angles of all paper and board aerogel samples with and without additives were in the range of $120-125^{\circ}$ (Figure 5). If the angle is less than $90^{\circ}$, the aerogels are hydrophilic, above $90^{\circ}$ they are hydrophobic (Ahmad \& Kan, 2016). 


\section{Sorption properties of the aerogel samples}

210 To show that the hydrophobised paper- and board-based cellulosic hydrogel samples with and

211 without additives are suitable for the uptake of hydrophobic liquids, the results of the capacity

212 determinations for biodiesel and MDO are shown below in figure parts a of figures 6-9. The

213 reuse efficiencies were calculated for each cycle and shown in figure parts $b$. The reuse

214 efficiencies of the samples indicate to what extent the previously measured sorption capacity is

215 available again after regeneration with ethanol. For this purpose, the first point of the sorption

216 capacity is taken as a reference point and set to $100 \%$.

217 Sorption capacity for biodiesel of the office paper based aerogel samples

218 The highest measured value of a sorption capacity of all composite samples was obtained by

219 paper-based cellulose aerogels with cellulose acetate in the first application to biodiesel: $32.25 \mathrm{~g}$

$220 \mathrm{~g}^{-1}$, the second highest by the composite sample with wool as an additive with $31.98 \mathrm{~g} \mathrm{~g}^{-1}$ only

221 slightly lower (Figure 6 a). These two samples showed higher sorption capacities than the control

222 sample. In the second sorption cycle, the sorption capacity for the cellulose aerogel/cellulose

223 acetate composite sample dropped below that of the control sample. This trend continued for this

224 sample in the following cycles. This was not the case for the other composite samples, which

225 showed a comparatively gentle decrease in sorption capacity compared to the previous value,

226 while consistently outperforming the control sample.

227

228 Figure 6. Results of the office paper-based aerogels maximum biodiesel sorption capacity (a)

229 and reuse efficiency of the aerogel sample on biodiesel by each cycle (b)

230

231 The reuse efficiency of each sample decreases slowly in this study and seems to approach a

232 constant value for all additives until the fourth cycle. However, in the fifth cycle there is a

233 sudden drop in the case of straw and cellulose acetate as additives and the control sample, most

234 pronounced for straw and the control sample. For cellulose acetate, this drop may not be

235 significant, as the drop in reuse efficiency is strong in all cycles.

236

237

238

239

240

241

242

243

244

245

\section{Sorption capacity for biodiesel of the cardboard-based aerogel samples}

The sorption capacities of the cardboard-based control sample are lower than those of the paper-

based sample (e.g. in the first cycle the sorption capacity of the cardboard-based sample is $26.1 \mathrm{~g}$ $\mathrm{g}^{-1}$ compared to the paper-based sample with $29.9 \mathrm{~g} \mathrm{~g}^{-1}$ ) (Figure 7). The sorption capacities of these additivated aerogels are generally lower than those of the paper-based samples. With the exception of the first cycle, the values for the sorption capacities of the mixed samples are lower than those of the control sample. Only aerogel samples mixed with cellulose acetate $\left(28.5 \mathrm{~g} \mathrm{~g}^{-1}\right)$ and this time with straw (26.8 $\mathrm{g} \mathrm{g}^{-1}$ ) show higher sorption capacities than the cardboard-based control sample. This is a clear difference to the paper-based samples. This is an unexpected result, as no distinction is made between paper and cardboard in the literature. 
247 Figure 7. Results of the cardboard-based aerogels maximum biodiesel sorption capacity (a) and reuse efficiency of the aerogel sample on biodiesel by each cycle (b)

Figure $7 \mathrm{~b}$ shows the reuse efficiency for algae, straw and cellulose acetate a strong decrease after the first washing cycle, again the strongest is that of cellulose acetate. Compared to the paperbased samples in Figure 6b, all cardboard-based samples, with the exception of the cellulose acetate-containing sample, are close together in an interval of 59-65\% in the fifth cycle, while the paper-based samples are more dispersed in an interval of $49-71 \%$.

255

256

257

258

259

260

261

262

263

264

265

266

267

268

269

270

271

272

273

274

275

276

277

278

279

280

281

282

\section{Sorption capacity for MDO of the office paper-based aerogel samples}

Except for the wool-added cellulose aerogel sample, all other cellulose aerogel composite samples perform worse than the control sample $\left(29.1 \mathrm{~g} \mathrm{~g}^{-1}\right)$ in the first application (Figure 8). In the second application, even the algae-added sample shows a higher sorption capacity than the control sample. In the third and fourth application, even straw-added samples show a higher, average sorption capacity. Only the cellulose-acetate-added samples consistently show the lowest sorption capacity in all cycles of this series.

Figure 8. Results of the office paper-based aerogels maximum MDO sorption capacity (a) and reuse efficiency of the aerogel sample on MDO by each cycle (b)

The reuse efficiencies of all samples decrease steadily (Figure 8b), but in contrast to the previously used biodiesels in Figure 6b, MDO seems to have a positive effect on the uniformity of the non-linear waste. Even samples additivated with cellulose acetate have a comparatively low drop of only about $20 \%$ in the second cycle relative to the initial value. However, the values for the reuse efficiency in the fifth cycle for all samples are significantly lower than the values of the paper-based samples in the biodiesel cycle. The algae-added samples again have the highest reuse efficiency as the paper-based samples in the biodiesel cycle in Figure $6 \mathrm{~b}$.

\section{Sorption capacity for MDO of the cardboard-based aerogel samples}

In this test series of the cardboard-based aerogel samples with MDO as test oil, wool as an additive again shows exceptionally high sorption capacities $\left(27.3 \mathrm{~g} \mathrm{~g}^{-1}\right)$ compared to the pure cardboard-based aerogel (Figure 9). In contrast to the previous test series, however, by the fourth cycle at the latest all added aerogel samples show a higher sorption capacity than the comparison sample.

Figure 9. Results of the cardboard-based aerogels maximum MDO sorption capacity (a) and reuse efficiency of the aerogel sample on MDO by each cycle (b) 
283 The positive influence on the reuse efficiency of the cellulose acetate-based aerogel samples over 284 the sorption-regeneration cycles (Figure $9 b$ ) is also shown by the comparatively high efficiency 285 of $58 \%$ in the fifth cycle, which is slightly higher than the paper-based samples in Figure $8 \mathrm{~b}$ and 286 almost $15 \%$ higher than the cardboard-based samples in the biodiesel cycle in Figure 7b.

287 Furthermore, again like the previous Figures 6-8, the sample with algae addition has the highest 288 reuse efficiency in the fifth cycle.

\section{The regeneration of the aerogel samples by ethanol}

290 Since the regeneration of the aerogels takes place between the sorption cycles by washing with 291 ethanol, the following chapter shows that ethanol is absorbed by the hydrophobised aerogels. For 292 this purpose, the sorption capacity over several cycles as well as the reuse efficiency were 293 presented in the same way as for the oils.

294

295

296

297

298

299

300

301

302

303

304

305

306

307

308

309

310

311

312

313

314

315

316

317

\section{Sorption capacity for ethanol of the office paper based aerogel samples}

The sorption capacity for ethanol decreases with each additional cycle (Figure 10a). The capacities are lower than for biodiesel or MDO. But similar to the series of paper-based aerogel samples with biodiesel, wool shows a very high capacity from the beginning $\left(24.4 \mathrm{~g} \mathrm{~g}^{-1}\right)$, straw and algae surpass the control sample from the second cycle on. Cellulose acetate composite samples show only a comparatively low capacity.

Figure 10. Results of the office paper-based aerogels maximum ethanol sorption capacity (a) and reuse efficiency (b)

There is a noticeable division into two groups, namely those of the aerogels added with algae, straw and wool and those of the control sample and the sample added with cellulose acetate. In the first group, the values are relatively close to each other during the 5 cycles, while the second group is also relatively close, but drops significantly more (Figure 6b).

\section{Sorption capacity for ethanol of the cardboard-based aerogel samples}

In the first four cycles, the highest sorption capacity was obtained with the cardboard-based aerogel samples containing wool $\left(21.2 \mathrm{~g} \mathrm{~g}^{-1}\right)$, while the sorption capacities of the algae and straw-doped cellulose aerogel samples were similar to those of the control sample (Figure 11a).

The lowest sorption capacity values in all cycles were obtained with aerogels containing cellulose acetate.

Figure 11. Results of the cardboard-based aerogels maximum ethanol sorption capacity (a) and reuse efficiency (b) 
318 In Figure 11b, as with the paper-based aerogels, a division into two groups can also be seen, but 319 the division is slightly different: the group with the better values for reuse efficiency during the

320

321

322

323

324

325

326

327

328

329

330

331

332

333

334

335

336

337

338

339

340

341

342

343

344

345

346

347

348

349

350

351 cycles consists of the samples with algae and straw additives and the control samples, while the samples with cellulose acetate and wool additives have on average about $10 \%$ lower reuse efficiency values. As in all previously presented series with the oils, in Figure 10 and 11 the algae/cellulose aerogel composite is the sample with the lowest waste and the highest value in the fifth cycle.

\section{Discussion}

\section{Density and porosity calculations of the aerogel samples}

Although paper and cardboard are made from the same raw material, this raw material is processed differently for these two products. Un-dyed paper is generally much lighter in colour than un-dyed cardboard and consists of thinner fibres. The more intensive refining process changes the composition of the cellulose fibres of the original raw material and results in different properties in the final product (Johansson A, 2011) (Wathen R, 2006) (Motamedian, Halilovic \& Kulachenk, 2019). This could possibly explain the differences in the densities of aerogels made from pure paper or board (Fig. 3). According to (Ioelovich, 2014), paperboard consists of $91 \%$ polymers such as cellulose $(61 \%)$, lignin $(18 \%)$ and hemicellulose (12\%) and $7 \%$ minerals, while office paper consists of only $68 \%$ polymeric components such as cellulose $(62 \%)$, lignin ( $1 \%)$ and hemicellulose $(5 \%)$ and $30 \%$ minerals.

The porosities of all samples (Fig. 4) are in a range characteristic of cellulose aerogels, as described in (Long, Weng \& Wang, 2018). The paper-based control sample of this study correspond to those in (Paulauskiene et al., 2020).

\section{Hydrophobicity of aerogel samples}

Cellulose aerogels, when not hydrophobicised, are hydrophilic like their raw material paper and cardboard and allow water to penetrate their highly porous structure. This was shown in ( $\mathrm{Li}$ et al., 2018b), where such aerogel samples serve as sorbents for heavy metal ions, or in (Mataar \& Boufi, 2017), where water-soluble dyes are sorbed. The hydrophobisation of the cellulose samples in this study prevents water penetration, as shown in Figure 5. The now hydrophobic samples only selectively sorb hydrophobic liquids (Hüsing \& Schubert, 1998), (Feng et al., 2015), which is also shown by the sorption tests on biodiesel and MDO.

A contact angle between $90^{\circ}$ and $150^{\circ}$ indicates a hydrophobic interaction between the water droplet and the samples. The measured contact angles indicate the hydrophobicity of the samples 
352 353

\section{4}

355

356

357

358

359

360

361

362

363

364

365

366

367

368

369

370

371

372

373

374

375

376

377

378

379

380

381

382

383

384

385

386

387

388

389

390

and are in the range also mentioned by the literature (Paulauskiene et al., 2020), (Zanini et al., 2017) for such samples.

\section{Sorption properties of the aerogel samples}

Sorption is the attachment of a liquid to the surface of the fibres and pores of the aerogel. Only van der Waals forces, such as dispersion and dipole interactions, act between absorpt and absorbent. The sorption capacity is determined by the effective surface area and the interstitial space. On the hydrophobised cellulose fibres from the paper and the cardboard as well as the additive, a film of these fluids is formed by the biodiesel, the MDO and also the ethanol. When the effective surfaces are wetted, the interstitial spaces are also filled.

As shown in Figure 6a, the sorption capacity of the wool and cellulose acetate additivated samples is about $14 \%$ higher than the control sample. The control sample shows a comparable sorption capacity as in (Paulauskiene et al., 2020). Wool and cellulose acetate thus have a capacity-increasing effect on the sorption of the biodiesel in the first application in Figure 6a. In the case of the cardboard-based aerogel samples (Figure 7a), the cellulose acetate also becomes sorption capacity enhancing in the first application, but instead of wool, straw is now the other additive with a slight capacity enhancing effect. In the case of MDO as the sorbent liquid, only wool has a capacity-increasing effect on the first application for both paper- and cardboard-based aerogel samples (Fig. 8a and 9a).

The capacity enhancing effect of the cellulose acetate additive could be explained by the already existing hydrophobicity of cellulose acetate. Cellulose acetate as an independent sorbent with good sorption capacities for oils was demonstrated in (Uebe, Paulauskiene \& Boikovych, 2021).

Wool already showed very good sorption properties as a single sorbent material against MDO in (Paulauskiene et al., 2014), so that it can be stated here that wool and cellulose aerogels complement each other as a composite. To a lesser extent, however, this also applies to the two other natural materials straw and algae.

The decrease of the sorption capacity in the following applications after the first one and the resulting reduced reuse efficiency (Figure 6-9 b) could be explained by the capillary effect due to the adhesion of oils with the hydrophobic methylsilane groups on the fibres. Under the given conditions, the samples always have an oil film remaining on the effective surface, which the ethanol cannot dissolve out.

In the case of the aerogel composite with straw, algae and wool, there is probably also a reinforcing effect of the cellulose matrix due to the similar morphology of the fibrous additives of the straw, algae or wool. Fibres in composites generally have a reinforcing effect on mechanical stability (Dowling, 2013), (Jozwiak-Niedzwiedzka \& Fantilli, 2020). This could lead to a reduced effect of the capillary effect during washing and subsequent drying, so that the reuse efficiency increases compared to the control sample.

In the case of cellulose acetate, the poor wettability of this material with water during the manufacturing process may have led to a lack of intimate mixing. The fibrous components of the cellulose acetate particles probably did not bond with the cellulose fibres of the base slurry, but 
391

392

393

394

395

396

397

398

399

400

401

402

403

404

405

406

407

408

409

410

411

412

413

414

415

416

417

418

419

420

421

422

423

424

425

426

427

428

remained as particles in the slurry, which according to (Dowling, 2013) can lead to rather poor mechanical stabilities depending on the particle size and material. Although cellulose acetate has a sorption capacity-increasing effect during the first application, the sorption capacity is probably brought back to the level of the non-added cellulose matrix or even below during washing and subsequent drying due to the capillary effect.

For a detailed discussion of the differences of the individual samples depending on the composition and the oils used is not possible, because to the author's knowledge no suitable methods are available for mapping the effective surface and simultaneously distinguishing the cellulose fibres from the additives in the aerogel samples.

A loss of the additives can be excluded, as the oil does not contain any visible residues of cellulose aerogel composite samples. This also applies to the still following cellulose aerogel composite samples. This also means that the cellulose aerogel composite samples can be used freely.

\section{The regeneration of the aerogel samples by ethanol}

Comparing the regeneration method of washing with ethanol used in this study with the squeezing method from (Paulauskiene et al., 2020), it can be seen that washing is clearly more gentle for the aerogel. Firstly, there is only a comparatively small drop in wool and algae to $70 \%$ relative to the initial value and secondly, the drop is continuous. In (Paulauskiene et al., 2020), the waste only occurs after the first squeezing to $40 \%$ reuse relative to the initial value. This abrupt drop in the second cycle (Fig 7b) is similar to the behaviour of the regeneration of cellulose acetate by squeezing in (Paulauskiene et al., 2020). The control sample and the one with the additional wool, on the other hand, show a rather slow and steady decrease in reuse efficiency. In contrast to (Paulauskiene et al., 2020), the reuse efficiency is higher with the exception of the sample with cellulose acetate, which indicates a much gentler process.

The amount of sorbed ethanol (Fig 10a, 11a) is lower in this work compared to marine diesel oil and biodiesel. (Cheng et al., 2017) find the same trend and attribute this to the lower density of ethanol compared to MDO and biodiesel. Wang et al. (Wang \& Liu, 2019) shows about equal sorption capacities for ethanol and diesel. Another reason could be the higher polarity of ethanol compared to biodiesel and MDO (Hoffmann et al., 2019) and because of the smaller molecular size, which would lead to smaller adhesion interaction with the methylsilanised cellulose. In the case of the low sorption capacity of cellulose acetate additivated aerogel samples, the insolubility of cellulose acetate in ethanol may also play a role. The decreasing sorption capacity of the aerogel samples for ethanol with each subsequent cycle can be explained by the subcritical drying after use. During the evaporation of the ethanol, the capillary forces between the pore walls and the ethanol are responsible for the shrinking of the sorption capacity (Hüsing \& Schubert, 1998). 


\section{Conclusions}

430 In summary, cellulose aerogel composites based on paper and cardboard were successfully

431 produced using wool, straw, algae and cellulose acetate and their additive-free control samples.

432 Although the cellulose aerogel literature does not distinguish between paper and cardboard as

433 cellulose sources, significant differences were found between these two types of cellulose

434 aerogels. The sorption capacity of the office paper-based aerogels is higher than that of the

435 cardboard-based aerogels. It can also be stated that the sorption capacity of the cellulose aerogel

436 can be improved by additives. But it probably depends on the processing of the additives with

437 the cellulose slurry. In contrast to fibrous additives, particular cellulose acetate from cigarette

438 butts have low reuse efficiency. It can also be noted that all cellulose aerogel composites can be

439 washed with ethanol to remove absorbed biodiesel and MDO and can thus be regenerated.

440 In conclusion, cellulose aerogel composites made of cellulose from paper waste mixed with wool

441 or cellulose acetate seem to be best suited to increase the capacity of the sorbent if the sorbent is

442 to be used only once for biodiesel, and only wool if it is also to be used once with MDO. If the

443 sorbent is to be used multiple times, wool or algae would be suitable additives. Wool as an

444 additive for cellulose aerogel composite as a sorbent is most universal for biodiesel or MDO and

445 also for the regenerant ethanol.

446

447

448

\section{Funding}

449 The authors received no fundings for this work.

450

\section{Competing Interests}

The authors declare there are no competing interests.

453

454

455

456

457

458

459

460

\section{Author Contributions}

Tatjana Paulauskiene, Jochen Uebe and Mindaugas Ziogas conceived and designed the experiments, performed them, analyzed the data, prepared the figures and tables, authored and reviewed drafts of the paper, and approved the final draft. 


\section{References}

462 Ahmad A, Kan C. 2016. A Review on Development and Applications of Bio-Inspired Superhydrophobic Textiles. Materials 9:892 DOI 10.3390/ma9110892.

Aluigi A, Vineis C, Ceria A, Tonin C. 2008. Composite biomaterials from fibre wastes: Characterization of wool-cellulose acetate blends. Composites, Part A 39:126-132 DOI 10.1016/j.compositesa.2007.08.022.

Bridgeford DJ, Turbak AF. 1969. Composite Cellulose-Wool Products. US-Patent 3,480,380.

Cheng H, Bowen G, Pennefather MP, Nguyen TX, Phan-Thien N, Duong HM. 2017. Cotton aerogels and cotton-cellulose aerogels from environmental waste for oil spillage cleanup. Materials \& Design 13:452-458 DOI 10.1016/j.matdes.2017.05.082.

Chollon G, Delettrez S, Langlais F. 2014. Chemical vapor infiltration and mechanical properties of carbon open-cell foams. Carbon 66:18-30 DOI 10.1016/j.carbon.2013.08.021.

Demirel Bayik G, Altin A. 2017. Production of sorbent from paper industry solid waste for oil spill cleanup. Marine Pollution Bulletin 125:341-349. DOI 10.1016/j.marpolbul.2017.09.040.

dos Santos EA, dos Santos FV, Freitas KM, Santos Pimenta LP, de Oliveira Andrate L, Marinho TA, de Avelar GF, de Silva AB, Ferreira RV. 2021. Cellulose acetate nanofibers loaded with crude annatto extract: Preparation, characterization, and in vivo evaluation for potential wound healing applications. Material Science and Engineering: C 118:111322 DOI 10.1016/j.msec.2020.111322.

Dowling NE. 2013. Mechanical Behavior of Materials - Engineering Methods of Deformation, Fracture and Fatigue. 4th ed., Publisher: Pearson.

Duong HM, Nguyen ST. 2016. Green recycled cellulose aerogels. In Green Polymer Composites Technology: Properties and Applications, 1st ed.; Inamuddin; Publisher Boca Raton, USA; pp. 239-252. https://doi.org/10.1201/9781315371184.

Feng J, Nguyen ST, Fan Z, Duong HM. 2015. Advanced fabrication and oil absorption properties of super hydrophobic recycled cellulose aerogels. Chemical Engineering Journal 270:168175. DOI 10.1016/j.cej.2015.02.034.

Ferronato N, Torreta V. 2019. Waste Mismanagement in Developing Countries: A Review of Global Issues. International Journal of Environmental Research and Public Health 16:1060 DOI 10.3390\%2Fijerph16061060.

Gilek M, Karlson M, Linke S, Smolarz K. 2016. Environmental Governance of the Baltic Sea, 1st ed; Publisher: Springer International Publishing, Heidelberg, Germany: pp. 265 DOI 10.1007/978-3-319-27006-7.

Hoffmann W, Langenhan J, Huhmann S, Moschner J, Chang R, Accorsi M, Seo J, Rademann J, Meijer G, Koksch B, Bowers MT, von Helden G, Pagel K. 2019. An Intrinsic Hydrophobicity Scale for Amino Acids and Its Application to Fluorinated Compounds, Angewandte Chemie International Edition 58:8216-8220 DOI 10.1002/anie.201813954

Hüsing N, Schubert U. 1998. Aerogels - Airy Materials: Chemistry, Structure and Properties. Angewandte Chemie International Edition 37:22-45 DOI 10.1002/(SICI)15213773(19980202)37:1/2\%3C22::AID-ANIE22\%3E3.0.CO;2-I.

Ifelebuegu AO, Lale EE, Mbanaso FU, Theophilus SC. 2018. Facile Fabrication of Recyclable, Superhydrophobic, and Oleophilic Sorbent from Waste Cigarette Filters for the Sequestration of Oil Pollutants from an Aqueous Environment. Process 6:140 DOI 10.3390/pr609014.

Ioelovich M. 2014. Waste Paper as Promising Feedstock for Production of Biofuel. Journal of Scientific Research and Reports 3:14 DOI 10.9734/JSRR/2014/8025.

ITOPF. Technical Information paper 8, Use of Sorbent Materials in Oil Spill Response, Available at https://www.itopf.org/fileadmin/data/Documents/TIPS\%20TAPS/TIP_8_Use_of_Sorbent_ Materials_in_Oil_Spill_Response.pdf(accessed 24 February 2021). 
510

511

512

513

514

515

516

517

518

519

520

521

522

523

524

525

526

527

528

529

530

531

532

533

534

535

536

537

538

539

540

541

542

543

544

545

546

547

548

549

550

551

552

553

554

555

556

557

Johansson A, 2011. Correlations between fibre properties and paper properties. Master thesis in Pulp Technology, KTH Institute of Technology, Sweden. Available at http://www.divaportal.org/smash/get/diva2:505453/FULLTEXT01.pdf (accessed 05 April 2021).

Jozwiak-Niedzwiedzka D, Fantilli AP. 2020. Wool-Reinforced cement based composites, Materials 13:3590 DOI 10.3390/ma13163590.

Kozyreff G, Wake G, Ockendor H, Summer RMW. 2003. Core bulk of wool fibres as a function of their curvature and diameter. Physical Letter A 314:428-433 DOI 10.1016/S03759601(03)00943-5.

Lam PS, Bi X, Mani S, Lim CJ, Womac AR, Hoque M, Peng J, JayaShankar T, Niami LJ, Nayaran S. 2007. Physical characterization of wet and dry wheat straw and switchgrass bulk and specific density. ASABE Paper 076058. St. Joseph, Mich., ASABE. Available at http://biomasslogistics.org/Publications/22lam.pdf accessed 24 February 2021.

Li H, Liu L, Yang F. 2013. Oleophilic polyurethane foams for oil spill cleanup. Procedia Environmental Science 18:528-533 DOI 10.1016/j.proenv.2013.04.071.

Li J, Wan C, Lu Y, Sun Q. 2014. Fabrication of cellulose aerogel from wheat straw with strong absorptive capacity. Frontiers of Agricultural Science and Engineering 1:46-52. DOI 10.15302/J-FASE-2014004.

Li Z, Gong L, Cheng X, He S, Li C, Zhang H. 2016. Flexible silica aerogel composites strengthened with aramid fibers and their thermal behavior. Materials \& Design 99:349-355 DOI 10.1016/j.matdes.2016.03.063.

Li Y, Liu X, Cai W, Cao Y, Sun Y, Tan F. 2018. Preparation of corn straw based spongy aerogel for spillage oil capture. Korean Journal of Chemical Engineering 35:1119-1127 DOI 10.1007/s11814-018-0010-3.

Li Z, Shao L, Ruan Z, Hu W, Lu L, Chen Y. 2018. Converting untreated waste office paper and chitosan into aerogel adsorbent for the removal of heavy metal ions. Carbohydrate Polymers 193:221-227 DOI 10.1016/j.carbpol.2018.04.003.

Lin R, Li A, Zheng T, Lu L, Cao Y. 2015. Hydrophobic and flexible cellulose aerogel as an efficient, green and reusable oil sorbent. RSC Advances 5:82027-82033 DOI 10.1039/C5RA15194E.

Linhares T, Pessoa de Amorim MT, Duraes L. 2019. Silica aerogel composites with embedded fibres: a review on their preparation, properties and applications. Journal of Material Chemistry A 7:22768-22802 DOI 10.1039/C9TA04811A.

Long LY, Weng YX, Wang YZ. 2018. Cellulose Aerogels: Synthesis, Applications, and Prospects. Polymers 10:623 DOI 10.3390/polym10060623.

Mataar W, Boufi S. 2017. Microporous cationic nanofibrillar cellulose aerogel as promising adsorbent of acid dyes. Cellulose 24:1001-1015 DOI 10.1007/s10570-016-1162-0

Meng-Chuen Chen D, Bodirsky BL, Krueger T, Mishra A, Popp A. 2020. The world's growing municipal solid waste: trends and impacts. Environmental Research Letters 15:074021 DOI 10.1088/1748-9326/ab8659.

Motamedian HR, Halilovic AE, Kulachenk A. 2019. Mechanisms of strength and stiffness improvement of paper after PFI refining with a focus on the effect of fines. Cellulose 26:40994124 DOI 10.1007/s10570-019-02349-5.

Nguyen ST, Feng J, Le NT, Le AT, Hoang N, Tan VBC, Duong HM. 2013. Cellulose Aerogel from Paper Waste for Crude Oil Spill Cleaning. Industrial \& Engineering Chemstry Research 52, 51:18386-18391, DOI 10.1021/ie4032567.

Paulauskiene T, Jucike I, Juscenko N, Baziuke D. 2014. The Use of Natural Sorbents for Spilled Crude Oil and Diesel Cleanup from the Water Surface. Water, Air, \& Soil Pollution 225:1959 DOI 10.1007/s11270-014-1959-0. 
558

559

560

561

562

563

564

565

566

567

568

569

570

571

572

573

574

575

576

577

578

579

580

581

582

583

584

585

586

587

588

589

590

591

592

593

594

595

596

597

598

599

600

601

602

603

604

Paulauskiene T, Uebe J, Karasu AU, Anne O. 2020. Investigation of Cellulose-Based Aerogels for Oil Spill Removal. Water, Air, \& Soil Pollution 231:424 DOI 10.1007/s11270-020-047991 .

Pereira LS, Feitosa JP, Morais JPS, de Freitas Rosa M. 2020. Bacterial cellulose aerogels: Influence of oxidation and silanization on mechanical and absorption properties, Carbohydrate Polymers 250:116927 DOI 10.1016/j.carbpol.2020.116927.

Saadoun IMK. 2014. Impact of Oil Spills on Marine Life. In Emerging Pollutants in the Environment, 1st ed.; Larramendy, M.L.; Soloneski, S.; Publisher: InTech Open DOI $10.5772 / 60455$.

Tran CD, Franja P, Mladen F, Benz G. 2016. Synthesis, structure and antimicrobial property of green composites from cellulose, wool, hair and chicken feather. Carbohydrate Polymers 151:1269-1276. DOI 10.1016/j.carbpol.2016.06.021.

Uebe J, Paulauskiene T, Boikovych K. 2021. Cost-effective and recyclable aerogels from cellulose acetate for oil spills clean-up. Environmental Science and Pollution Research, (accepted) DOI 10.1007/s11356-021-13369-9.

Wang H, Xu J, Zhao W, Zhang J. 2014. Effects and Risk Evaluation of Oil Spillage in the Sea Areas of Changxing Island. International Journal of Environmental Research and Public Health 11:8491-8507 DOI 10.3390\%2Fijerph110808491.

Wang J, Liu S. 2019. Remodeling of raw cotton fiber into flexible, squeezing-resistant macroporous cellulose aerogel with high oil retention capability for oil/water separation, Separation and Purification Technology 221:303-310 DOI 10.1016/j.seppur.2019.03.097.

Wang Z, Qiao X, Sun K. 2018. Rice straw cellulose nanofibrils reinforced poly(vinyl alcohol) composite films. Carbohydrate Polymers 197:442-450 DOI 10.1016/j.carbpol.2018.06.025.

Wathen R, 2006. Studies on fiber strength and its effect on paper properties. Disseration, Helsinki University of Technology, Finland. Available at http://lib.tkk.fi/Diss/2006/isbn9512285258/isbn9512285258.pdf (accessed 05 April 2021).

Xiao Y, Li L, Liu F, Zhang S, Feng J, Jiang Y, Feng J. 2020. Compressible, Flame-Resistant and Thermally Insulating Fiber-Reinforced Polybenzoxazine Aerogel Composites. Materials 13:2809 DOI 10.3390/ma13122809.

Yan C, Wang R, Wan J, Zhang Q, Xue S, Wu X, Zhang J, Zhang J, Lu Y, Cong W. 2016. Cellulose/microalgae compositefilms prepared in ionic liquids. Algal Research 20:135-141 DOI 10.1016/j.algal.2016.09.024.

Yousefi H, Faezipour M, Nishino T, Shakeri A, Ebrahimi G. 2011. All-cellulose composite and nanocomposite made from partially dissolved micro- and nanofibers of canola straw. Polymer Journal 43:559-564 DOI 10.1038/pj.2011.31.

Zamparas M, Tzivras D, Dracopoulos V, Ioannides T. 2020. Application of Sorbents for Oil Spill Cleanup Focusing on Natural-Based Modified Materials: A Review. Molecules 25:22 DOI 10.3390/molecules25194522.

Zanini M, Lavoratti A, Kunz Lazzari L, Galiotto D, Pagnocelli M, Baldasso C, Zattera AJ. 2017. Producing aerogels from silanized cellulose nanofiber suspension. Cellulose 24:769779 DOI 10.1007/s10570-016-1142-4.

Zhang J, Cao Y, Feng J, Wu P. 2012. Graphene-Oxide-Sheet-Induced Gelation of Cellulose and Promoted Mechanical Properties of Composite Aerogels. Journal of Physical Chemistry C 116:8063-8068 DOI 10.1021/jp2109237.

Zhang X, Yu Y, Jiang Z, Wang H. 2015. The effect of freezing speed and hydrogel concentration on the microstructure and compressive performance of bamboo-based cellulose aerogel. Journal of Wood Science 61:595-601 DOI 10.1007/s10086-015-1514-7.

Peer] reviewing PDF | (2021:04:59840:1:1:NEW 9 Jun 2021) 
605 606 607 608 609 610 611

612
Zhen LW, Thai QB, Nguyen TX, Le DK, Wei Lee JK, Xiang YQ, Duong HM. 2019. Recycled Cellulose Aerogels from Paper Waste for a Heat Insulation Design of Canteen Bottles. Fluids 4:174 DOI 10.3390/fluids4030174.

Zhu H, Lu X, Dai H. 2018. Surface-flow constructed wetlands dominated by Cladophora for reclaiming nutrients in diffuse domestic effluent. Chemosphere, 195:524-530 DOI 10.1016/j.chemosphere.2017.12.103. 
Figure 1

Aerogels production scheme; examples of aerogels raw materials and additives: a) office paper; b) cardboard; c) wool; d) straw; e) algae; f) cellulose acetate

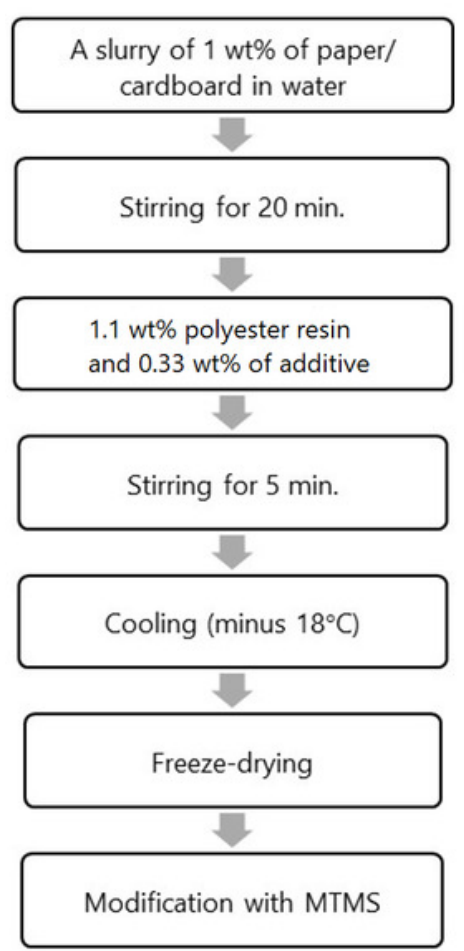

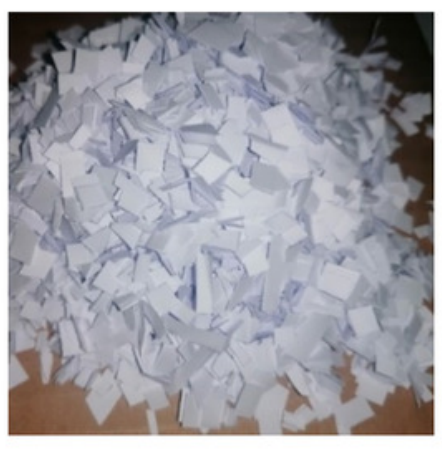

a

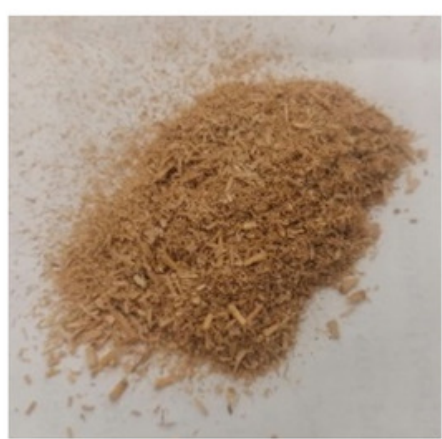

$\mathrm{d}$

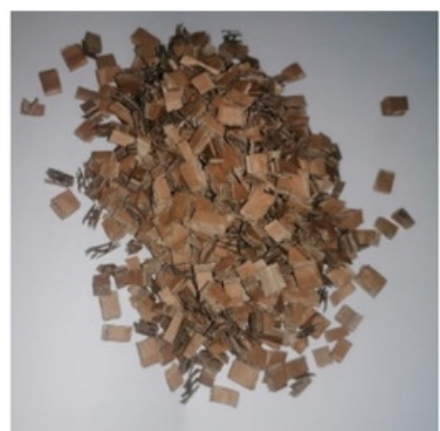

b

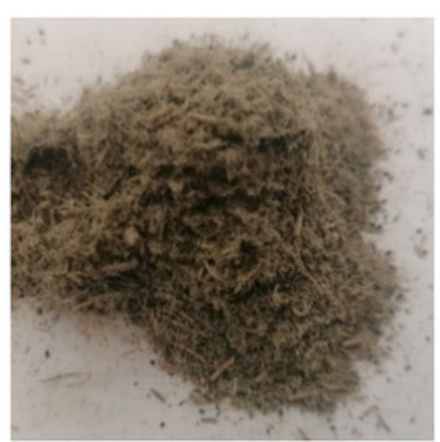

e

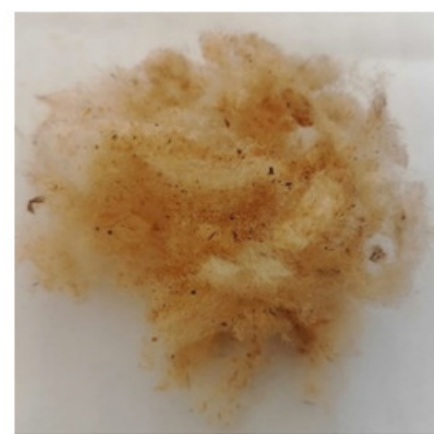

c

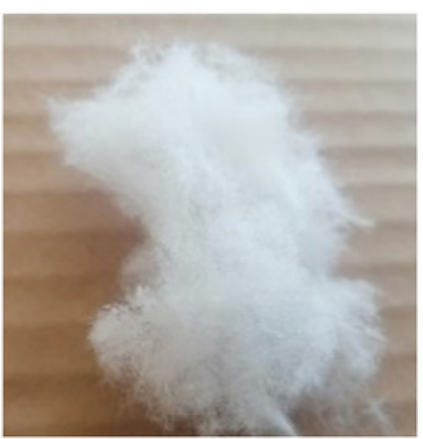

f 


\section{Figure 2}

Photograph of an aerogel modification: aerogel samples of office paper are white, aerogel samples of cardboard are brownish

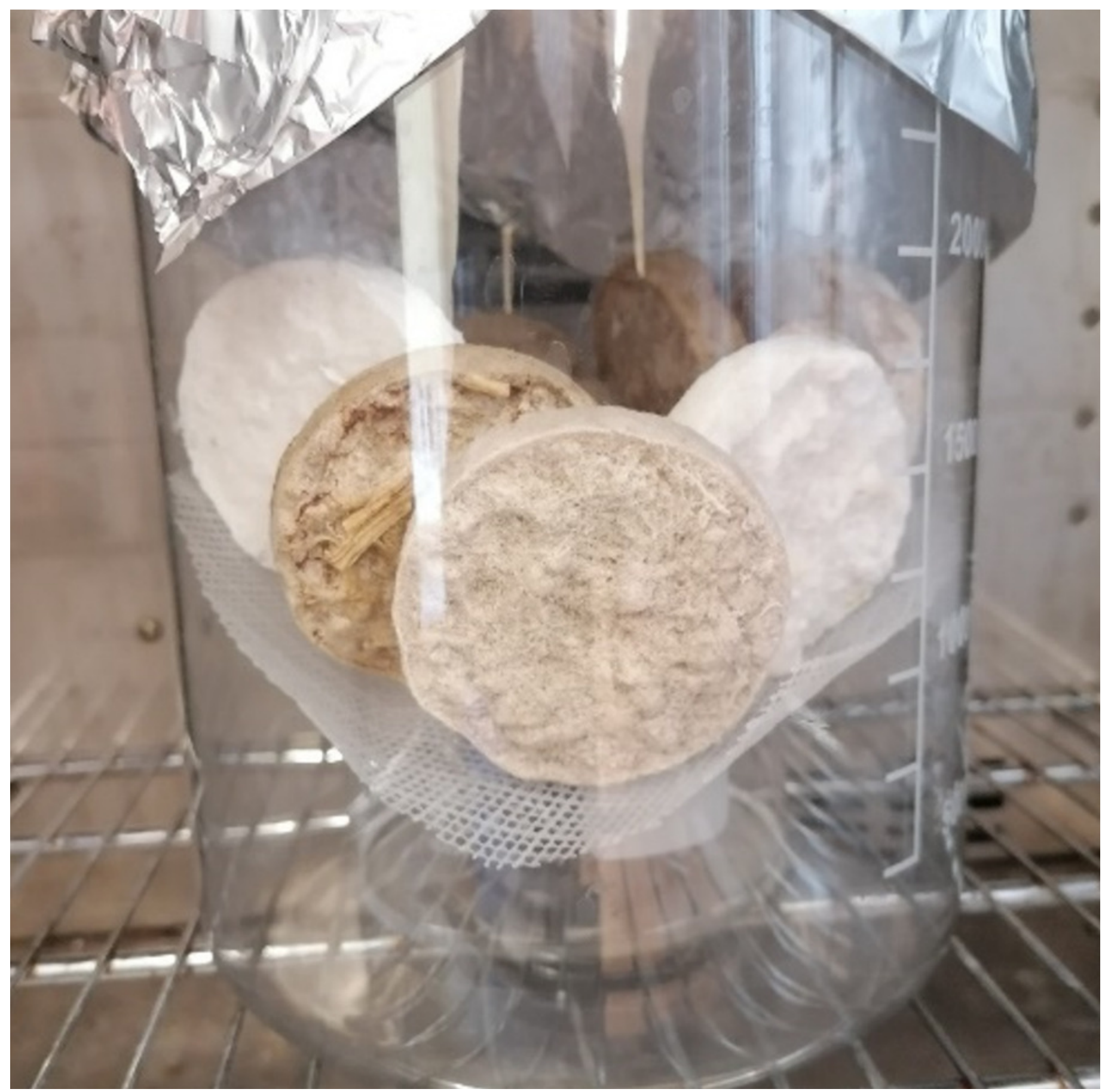


Figure 3

Density of aerogels produced from office paper and cardboard with organic additives

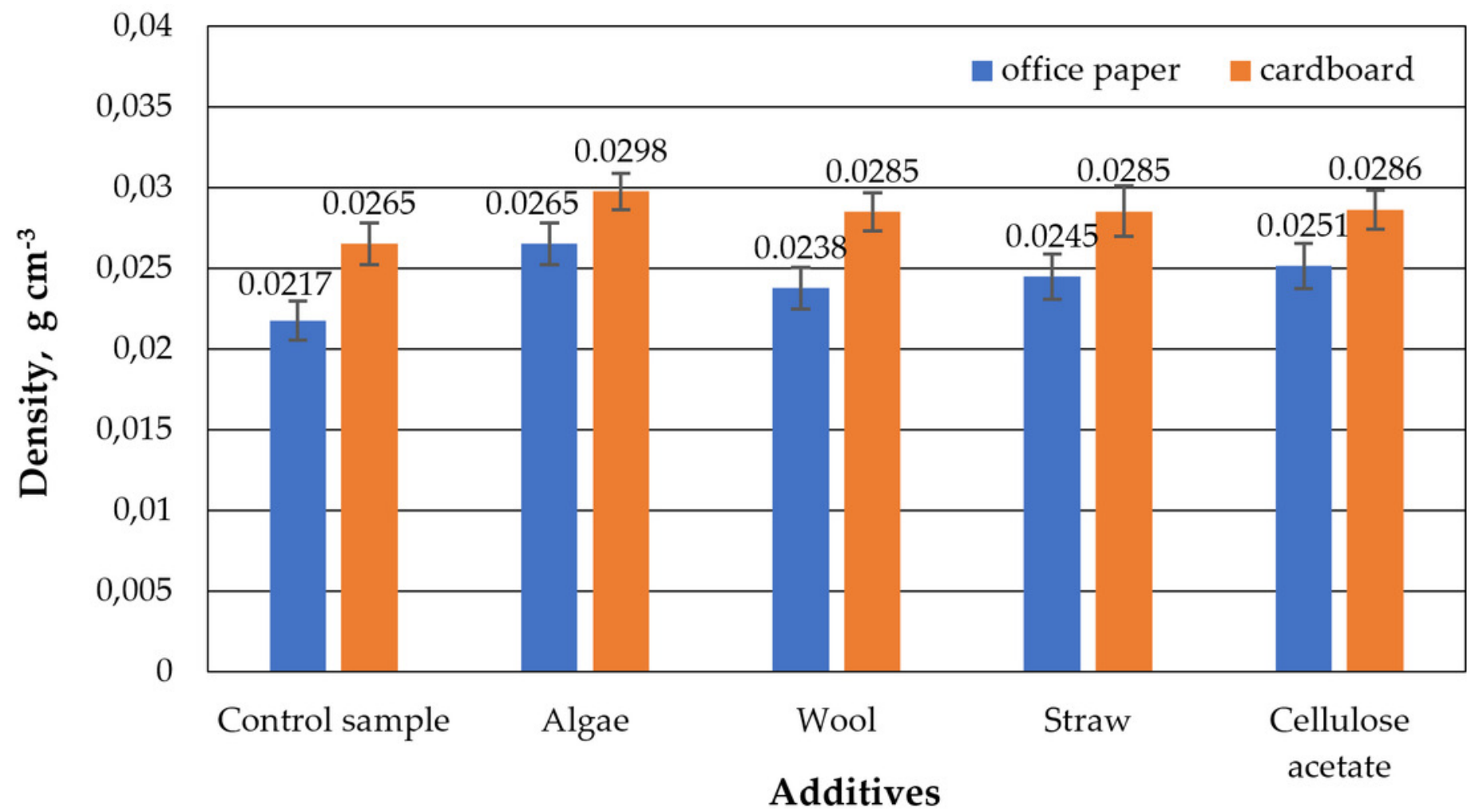


Figure 4

Porosity of aerogels produced from office paper and cardboard with organic additives

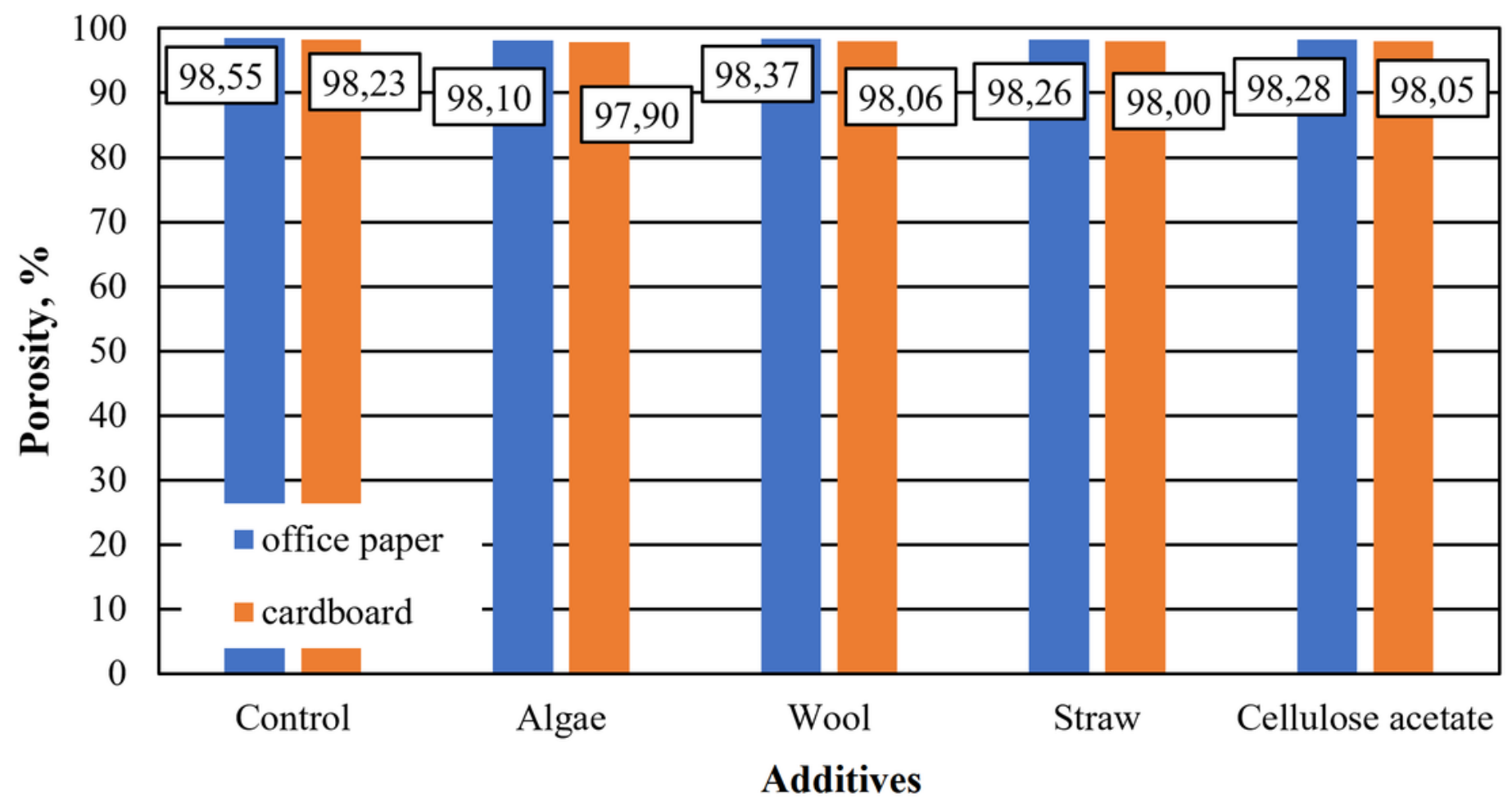




\section{Figure 5}

Water droplet on a sample of aerogel: aerogel photo with water droplet on the top (a), close look to water droplet for contact angle with aerogel (b)

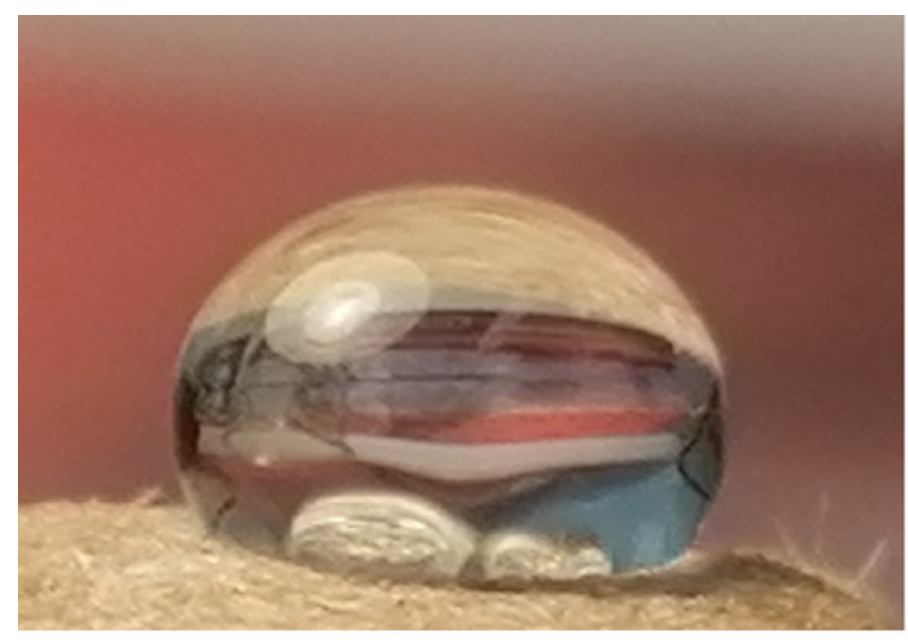

(a)

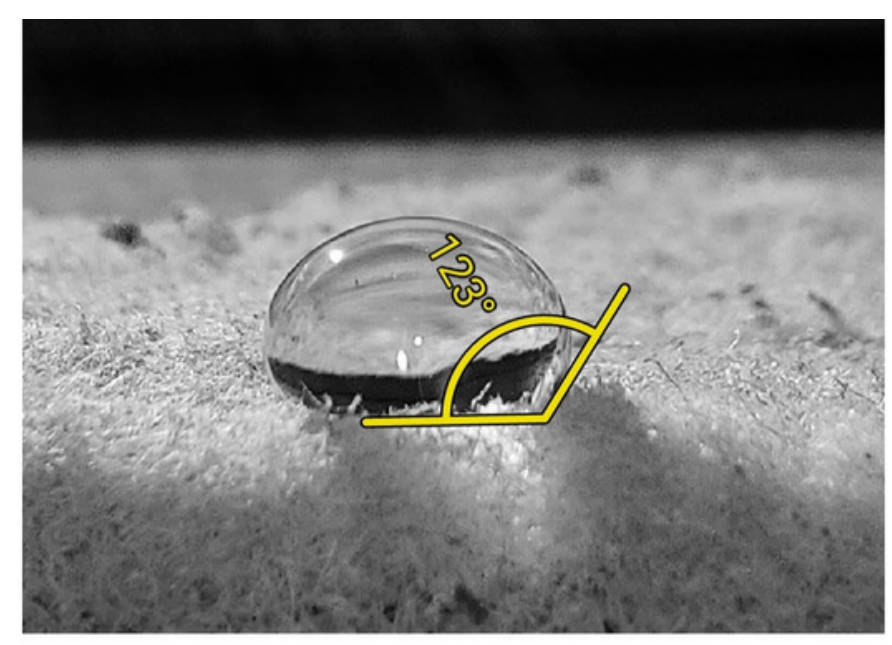

(b) 
Figure 6

Results of the office paper-based aerogels maximum biodiesel sorption capacity (a) and reuse efficiency of the aerogel sample on biodiesel by each cycle (b) 

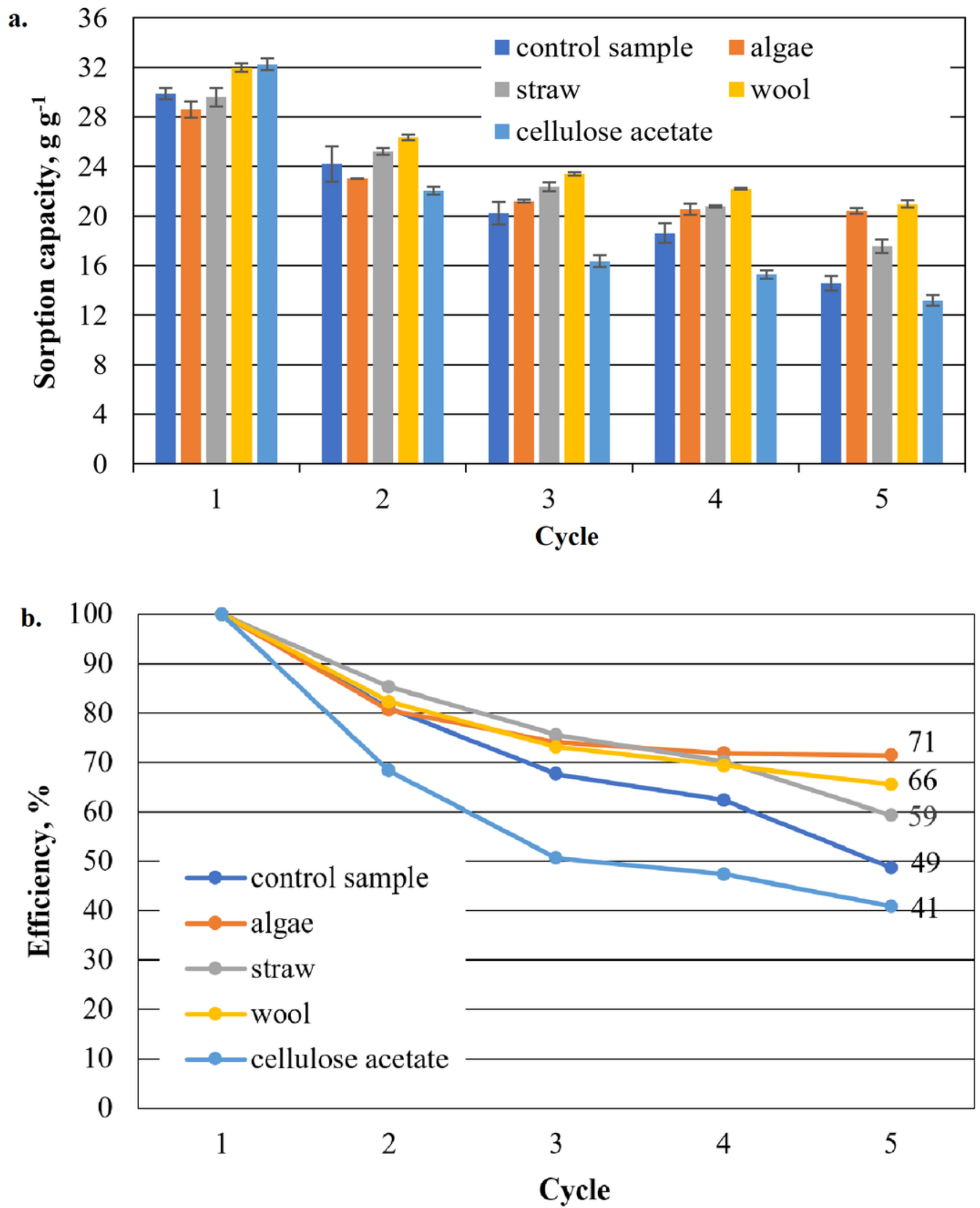
Figure 7

Results of the cardboard-based aerogels maximum biodiesel sorption capacity (a) and reuse efficiency of the aerogel sample on biodiesel by each cycle (b) 

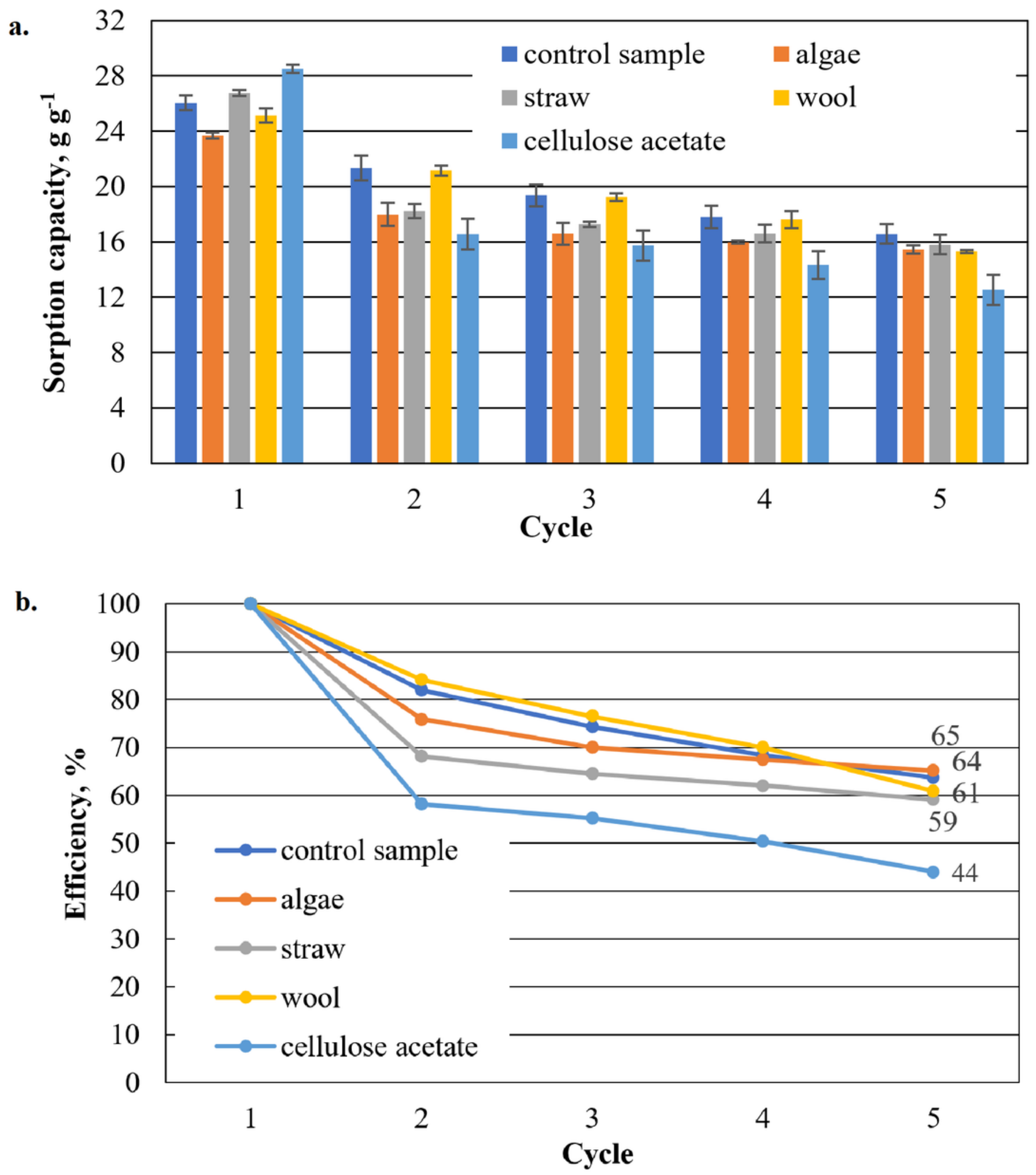
Figure 8

Results of the office paper-based aerogels maximum MDO sorption capacity (a) and reuse efficiency of the aerogel sample on MDO by each cycle (b) 

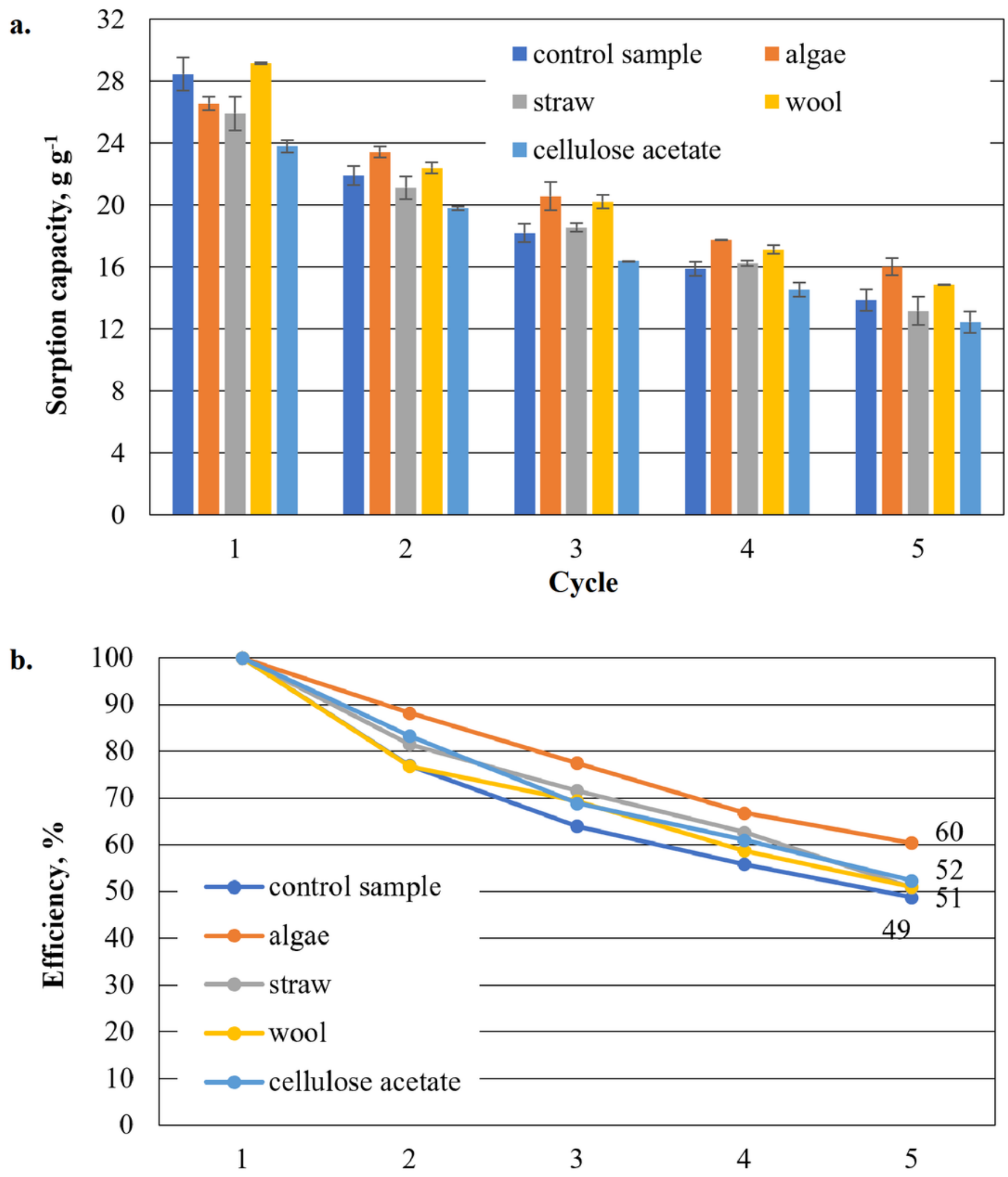

\section{Cycle}


Figure 9

Results of the cardboard-based aerogels maximum MDO sorption capacity (a) and reuse efficiency of the aerogel sample on MDO by each cycle (b) 

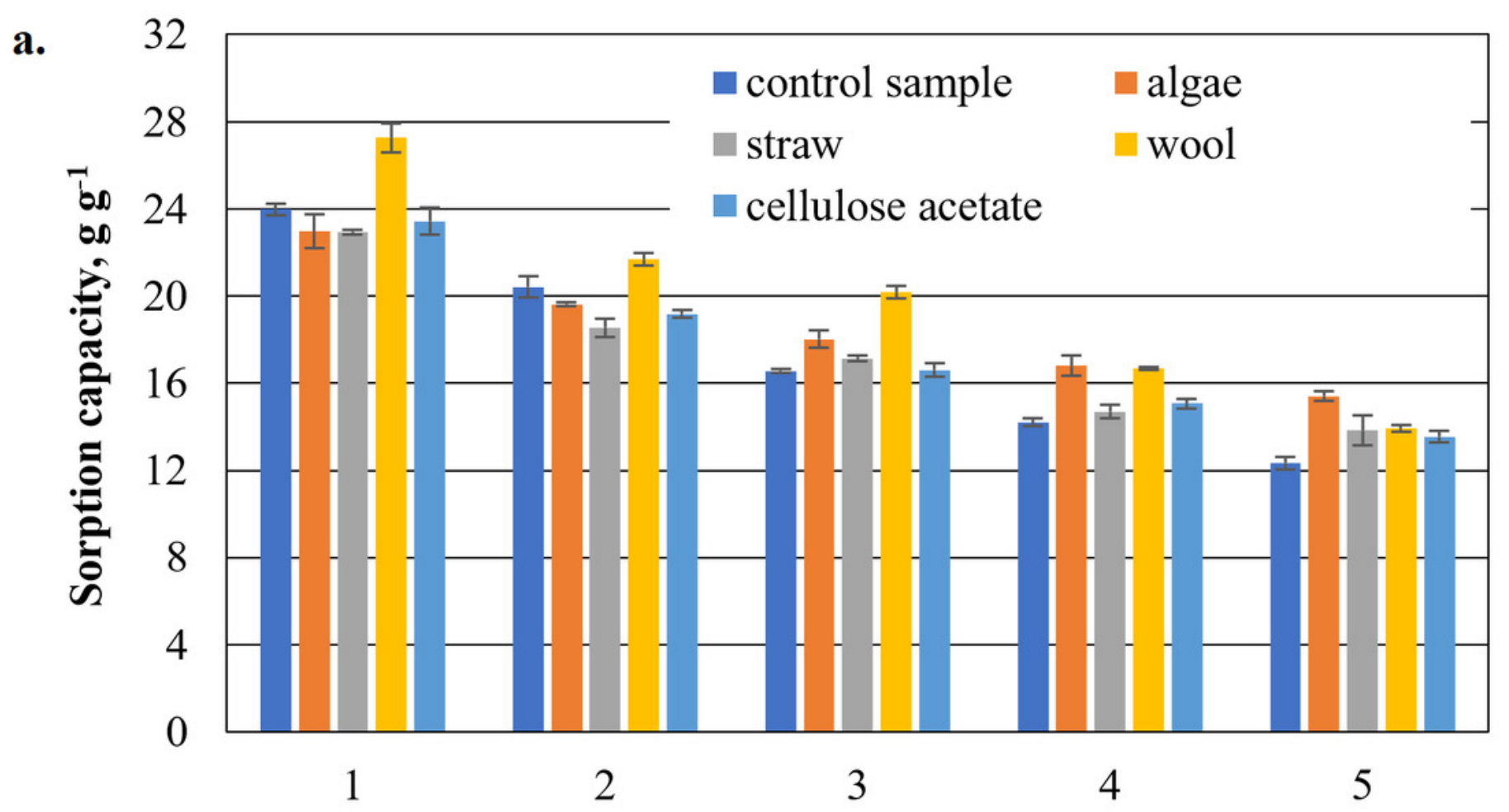

\section{Cycle}

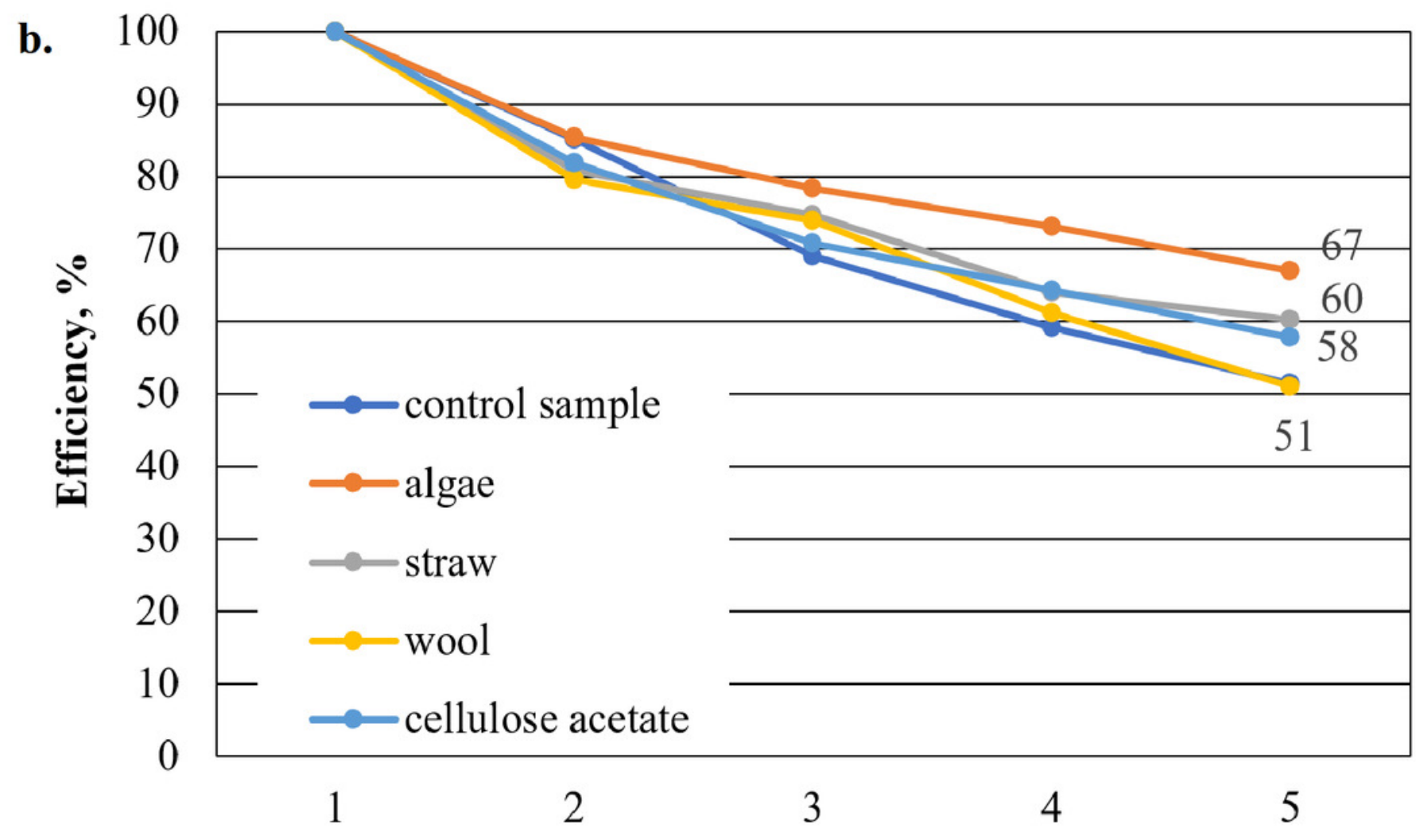

\section{Cycle}


Figure 10

Results of the office paper-based aerogels maximum bioethanol sorption capacity (a) and reuse efficiency (b) 


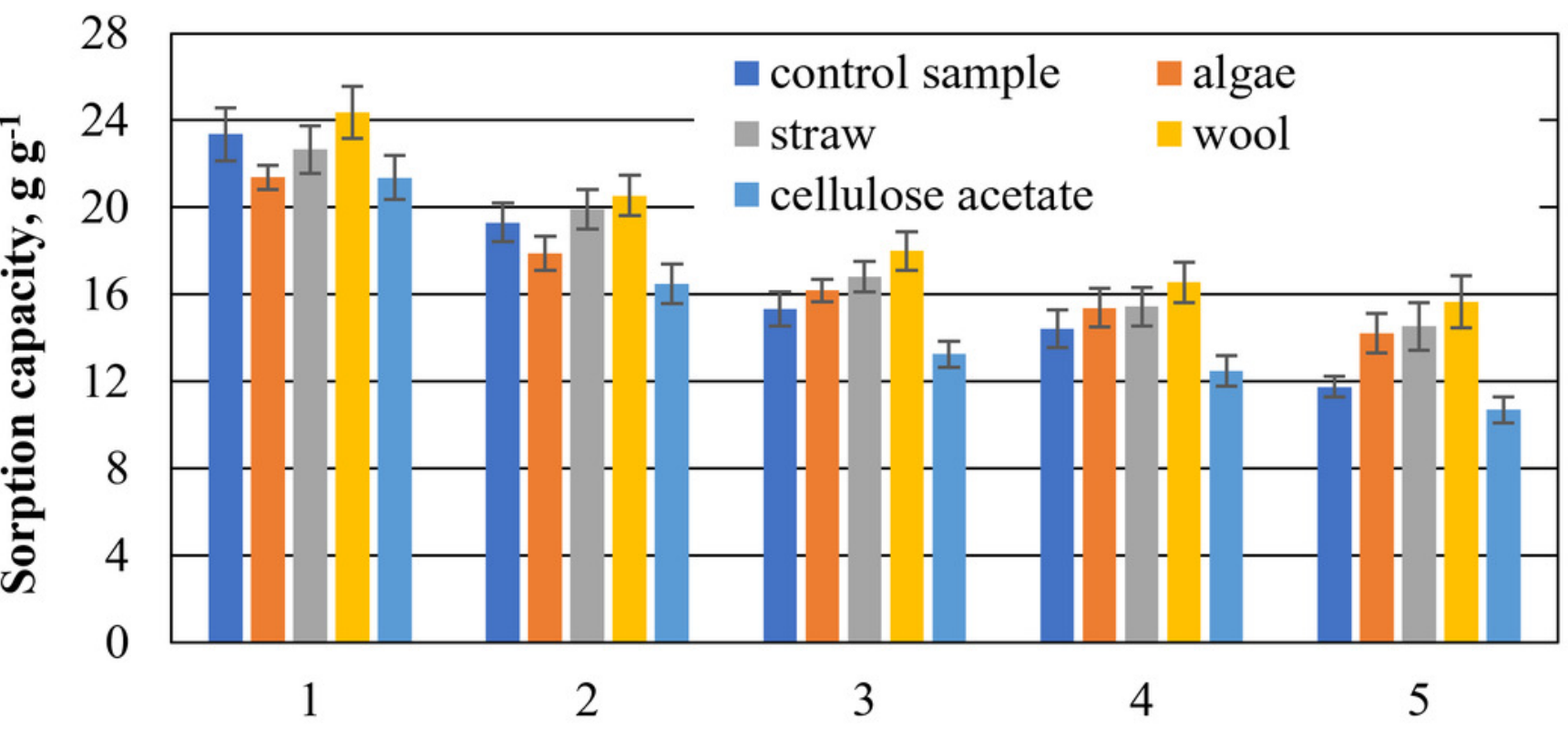

Cycle

b.

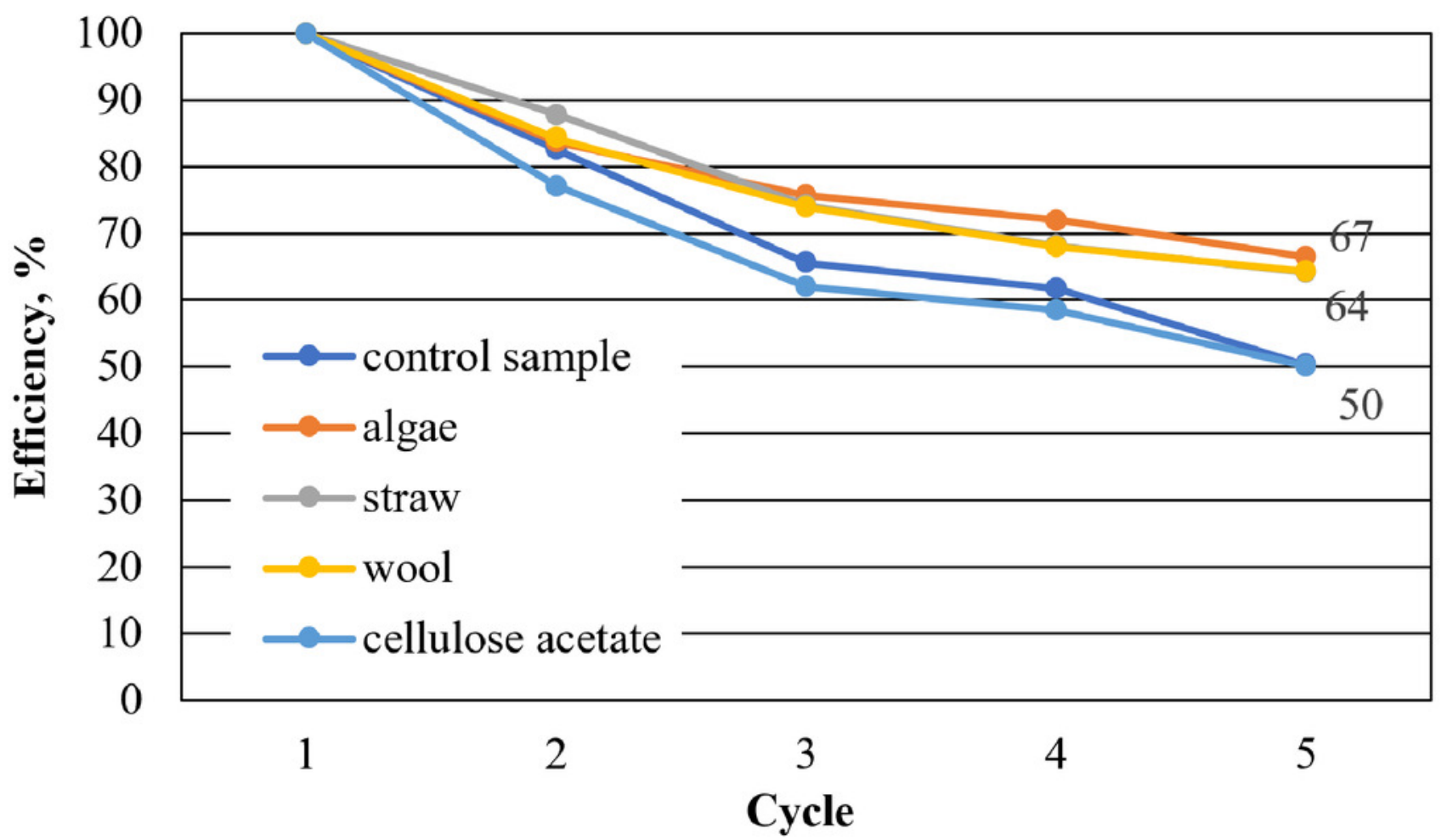


Figure 11

Results of the cardboard-based aerogels maximum bioethanol sorption capacity (a) and reuse efficiency $(b)$ 
a.

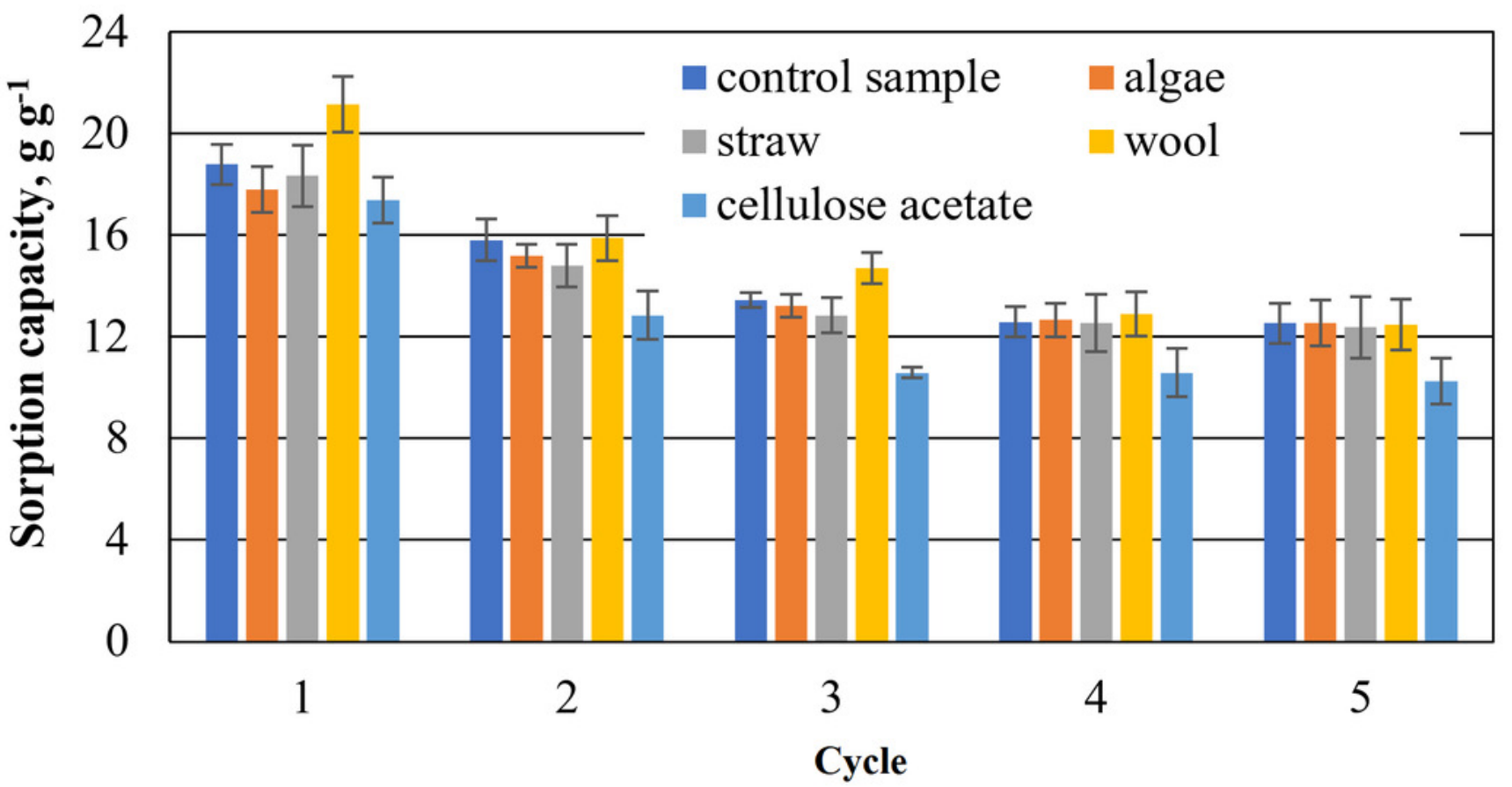

b.

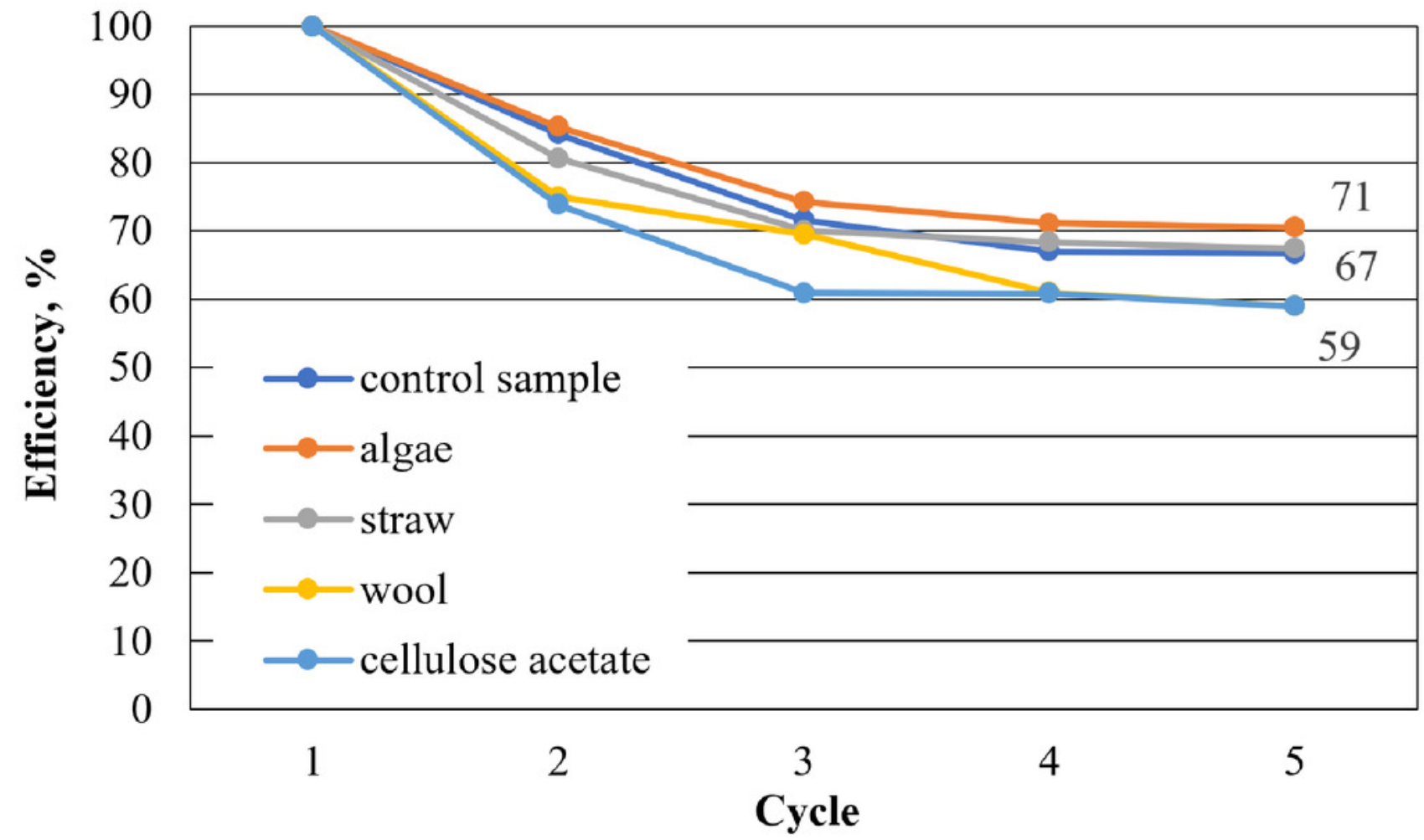

